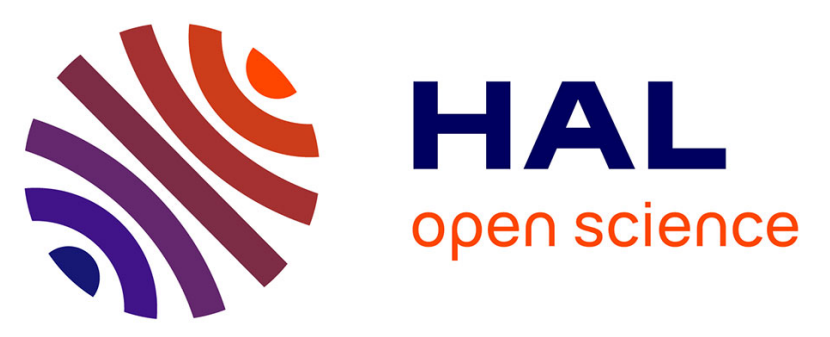

\title{
Position paper for management of elderly patients with pacemakers and implantable cardiac defibrillators Groupe de rythmologie et stimulation cardiaque de la Société française de cardiologie et Société française de gériatrie et gérontologie.
}

Laurent Fauchier, Christine Alonso, Frédéric Anselme, Hugues Blangy, Pierre Bordachar, Serge Boveda, Nicolas Clementy, Pascal Defaye, Jean-Claude Deharo, Patrick Friocourt, et al.

\section{To cite this version:}

Laurent Fauchier, Christine Alonso, Frédéric Anselme, Hugues Blangy, Pierre Bordachar, et al.. Position paper for management of elderly patients with pacemakers and implantable cardiac defibrillators Groupe de rythmologie et stimulation cardiaque de la Société française de cardiologie et Société française de gériatrie et gérontologie.. Gériatrie et psychologie \& neuropsychiatrie du vieillissement, 2016, 14 (3), pp.239-64. 10.1684/pnv.2016.0628 . hal-01820281

\section{HAL Id: hal-01820281 \\ https://hal.science/hal-01820281}

Submitted on 5 Dec 2019

HAL is a multi-disciplinary open access archive for the deposit and dissemination of scientific research documents, whether they are published or not. The documents may come from teaching and research institutions in France or abroad, or from public or private research centers.
L'archive ouverte pluridisciplinaire HAL, est destinée au dépôt et à la diffusion de documents scientifiques de niveau recherche, publiés ou non, émanant des établissements d'enseignement et de recherche français ou étrangers, des laboratoires publics ou privés. 


\section{Position paper for management of elderly}

patients with pacemakers and implantable cardiac defibrillators: Groupe de Rythmologie et Stimulation Cardiaque de la Société Française de Cardiologie and Société Française de Gériatrie et Gérontologie

Points de vue d'experts du Groupe de rythmologie et stimulation cardiaque de la Société française de cardiologie et de la Société française de gériatrie et gérontologie sur la prise en charge des sujets âgés avec stimulateur ou défibrillateur cardiaque implantable

Laurent Fauchier $^{\mathrm{a}, *}$, Christine Alonso ${ }^{\mathrm{b}}$,

Frederic Anselme ${ }^{c}$, Hugues Blangy ${ }^{d}$,

Pierre Bordachar ${ }^{e}$, Serge Boveda ${ }^{\dagger}$, Nicolas Clementy a, Pascal Defaye ${ }^{\mathrm{g}}$, Jean-Claude Deharo ${ }^{h}$, Patrick Friocourt ${ }^{i}$, Daniel Gras ${ }^{j}$, Franck Halimi ${ }^{k}$, Didier Klug ', Jacques Mansourati ${ }^{\mathrm{m}}$, Benjamin Obadia ${ }^{\mathrm{h}}$, Jean-Luc Pasquién ${ }^{n}$, Dominique Pavin ${ }^{\circ}$, Nicolas Sadoul $^{\mathrm{d}}$, Jerome Taieb ${ }^{p}$, Olivier Piot ${ }^{q}$, Olivier Hanon ${ }^{r}$

a CHU Trousseau, université François-Rabelais, 37044 Tours, France

b Clinique Ambroise-Paré, 92200 Neuilly-sur-Seine, France

Abbreviations: ADL, activities of daily living; AF, atrial fibrillation; AHRE, atrial high rate episode; AV, atrioventricular; CGA, Comprehensive Geriatric Assessment; CRT, cardiac resynchronization therapy; CRT-D, CRT with defibrillation; CRT-P, CRT with pacemaker; HF, heart failure; ICD, implantable cardioverter defibrillator; LV, left ventricular; MRI, magnetic resonance imaging; NYHA, New York Heart Association; PM, pacemaker; PVB, premature ventricular beat; SCD, sudden cardiac death; VT, ventricular tachycardia.

* Corresponding author. Cardiologie et électrophysiologie cardiaque, CHU Trousseau, 37044 Tours, France.

E-mail address: Ifau@med.univ-tours.fr (L. Fauchier). 
c Rouen University Hospital, 76031 Rouen, France

d Institut Lorrain du Cour et des Vaisseaux, CHU de Nancy, 54500 Vandouvre-lès-Nancy,

France

e CHU Haut Lévêque, Bordeaux, 33600 Pessac, France

${ }^{f}$ Clinique Pasteur, 31300 Toulouse, France

${ }^{2} \mathrm{CHU}$ Michallon, 38700 Grenoble, France

${ }^{\text {h }}$ CHU La Timone, 13385 Marseille, France

' Centre hospitalier, 41016 Blois, France

${ }^{j}$ Nouvelles cliniques nantaises, 44202 Nantes, France

k Hôpital privé de Parly 2, 78150 Le Chesnay, France

' CHRU de Lille, 59000 Lille, France

m Brest University Hospital, 29200 Brest, France

${ }^{n}$ CHU Arnaud-de-Villeneuve, 34090 Montpellier, France

- CHU Pontchaillou, 35000 Rennes, France

${ }^{\mathrm{P}}$ Centre hospitalier, 13616 Aix-en-Provence, France

${ }^{q}$ Centre cardiologique du Nord, 93200 Saint-Denis, France

r Hôpital Broca, 75013 Paris, France

\section{KEYWORDS}

\section{Cardiac pacing;} Implantable cardioverter defibrillator; Cardiac resynchronization therapy; Elderly

\section{MOTS CLÉS}

Pacemaker ; Défibrillateur automatique implantable ; Resynchronisation cardiaque ; Sujet âgé
Summary Despite the increasingly high rate of implantation of pacemakers (PMs) and implantable cardioverter defibrillators (ICDs) in elderly patients, data supporting their clinical and cost-effectiveness in this age stratum are ambiguous and contradictory. We reviewed the data regarding the applicability, safety and effectiveness of conventional pacing, ICDs and cardiac resynchronization therapy (CRT) in elderly patients. Although periprocedural risk may be slightly higher in the elderly, the implantation procedure for PMs and ICDs is still relatively safe in this age group. In older patients with sinus node disease, the general consensus is that DDD pacing with the programming of an algorithm to minimize ventricular pacing is preferred. In very old patients presenting with intermittent or suspected atrioventricular block, VVI pacing may be appropriate. In terms of correcting potentially life-threatening arrhythmias, the effectiveness of ICD therapy is similar in older and younger individuals. However, the assumption of persistent ICD benefit in the elderly population is questionable, as any advantageous effect of the device on arrhythmic death may be attenuated by higher total non-arrhythmic mortality. While septuagenarians and octogenarians have higher annual all-cause mortality rates, ICD therapy may remain effective in selected patients at high risk of arrhythmic death and with minimum comorbidities despite advanced age. ICD implantation among the elderly, as a group, may not be cost-effective, but the procedure may reach cost-effectiveness in those expected to live more than 5-7 years after implantation. Elderly patients usually experience significant functional improvement after CRT, similar to that observed in middle-aged patients. Management of CRT non-responders remains globally the same, while considering a less aggressive approach in terms of reinterventions (revision of left ventricular [LV] lead placement, addition of a right ventricular or LV lead, LV endocardial pacing configuration). Overall, physiological age, general status and comorbidities rather than chronological age per se should be the decisive factors in making a decision about device implantation selection for survival and well-being benefit in elderly patients.

(c) 2016 Elsevier Masson SAS. All rights reserved.

Résumé Malgré le taux de plus en plus élevé d'implantation de pacemaker (PM) ou de défibrillateurs automatiques implantables (DAl) chez les patients âgés, l'efficacité clinique et le rapport coût/efficacité des prothèses électriques dans cette population restent discutés. Nous discutons ici les données concernant l'applicabilité, la sécurité et l'efficacité de la stimulation conventionnelle, du DAl et de la resynchronisation cardiaque chez les patients âgés. Le risque péri-procédural peut être légèrement plus élevé chez les personnes âgées, mais l'implantation de PM ou de DAl se fait avec une relative sécurité pour ces patients. Chez les patients âgés souffrant d'une maladie du nœud sinusal, un consensus général est que 
la stimulation double chambre, ainsi que la programmation d'un algorithme pour réduire au minimum la stimulation ventriculaire est préférable. Pour les patients très âgés avec un bloc atrioventriculaire intermittent ou suspecté, la stimulation VVI peut être appropriée. Concernant les arythmies ventriculaires potentiellement mortelles, l'efficacité du traitement par DAl est comparable chez les personnes âgées et les sujets plus jeunes. Toutefois, l'hypothèse d'un bénéfice du DAl dans la population âgée est discutable, car le bénéfice sur la mort arythmique peut être atténué par une mortalité totale ou non rythmique supérieure. Alors que septuagénaires et octogénaires ont des taux annuels plus élevés de mortalité totale, le traitement par DAl peut rester efficace chez certains patients à haut risque de décès par arythmie et avec des comorbidités limitées malgré l'âge avancé. L'implantation de DAl chez les personnes âgées peut avoir un rapport coût/efficacité défavorable à l'échelle de la population totale, mais la procédure est économiquement rentable si l'on considère les patients avec une espérance de vie d'au moins 5-7 ans après l'implantation. Les patients âgés ont habituellement une amélioration fonctionnelle significative après resynchronisation cardiaque par stimulation biventriculaire, similaire à celle observée chez les patients d'âge moyen. La prise en charge des non répondeurs à la resynchronisation reste globalement la même, tout en tenant compte d'une approche moins agressive en termes de ré-interventions (repositionnement de sonde VG, ajout d'une sonde VD ou VG, ou stimulation endocardique VG). Au total, l'âge physiologique, le statut général et les comorbidités (plutôt que l'âge chronologique en soi) devraient être les facteurs décisifs lors de prise de décision pour l'implantation d'une prothèse cardiaque électrique pour un bénéfice en termes de survie et de qualité de vie chez les patients âgés.

\section{Background}

Pacemakers (PMs) and implantable cardioverter defibrillators (ICDs) are well-established therapies in modern cardiology. Knowledge of the natural history of severe bradyarrhythmias comes from very old studies performed at the beginning of the PM era. In some situations, the efficacy of pacing is therefore inferred, rather than proven by randomized clinical trials. Several randomized controlled trials have shown improved outcomes with cardiac resynchronization therapy (CRT) in appropriately selected patients with systolic heart failure (HF) and evidence of dyssynchrony. The beneficial effect of ICDs in the prevention of sudden cardiac death $(\mathrm{SCD})$ has also been well demonstrated in several randomized trials [1-7]. Each year in France, PMs and ICDs are implanted in around 65,000 and 15,000 patients, respectively. Studies have shown that around $75 \%$ of PMs and $30-35 \%$ of ICDs and CRT devices are inserted in individuals aged $\geq 75$ years [ $8-10]$. As the population ages, the number of elderly patients considered for electrical device implantation is unequivocally increasing $[11,12]$. However, data supporting the clinical effectiveness of devices in this age stratum may be contradictory [1,13-19]. Although guidelines state that ICD implantation is "rarely appropriate" in nonagenarians [18], they do not refer to any specific age limits. The few elderly patients selected for admission into large randomized trials may not be representative of the real-world elderly population.

We aimed to review the current literature regarding the potential benefit of cardiac pacing, CRT and ICDs in elderly and very elderly populations. The applicability of the use of cardiac electrical devices in this age group, and their safety, clinical effectiveness and cost-effectiveness were addressed, and we tried to distinguish which patients in this age stratum are more likely to benefit from these therapies.

\section{Epidemiology of rhythm disturbances in the elderly}

\section{Conduction disorders}

Apoptosis and fibrofatty infiltration are present during normal ageing of nodal tissue. In addition, in the elderly, sinus node automaticity and conduction disorders may be severely depressed by drugs. In the sinus node, nodal cell rarefaction, perinodal fibrosis and adrenergic receptor damage are partially offset by the decrease in parasympathetic basal tone. In a 75-year-old subject, the number of sinus node cells has declined to $10 \%$ compared with in a 20 -year-old subject. Membrane channel alterations also impair sinus node automaticity. As a consequence, the intrinsic heart rate, obtained after autonomous blockade, decreases with age. The resting heart rate is not affected, while the exercise heart rate is, leading to reduced exercise capacity. The maximum heart rate decreases by $0.7-1$ beat per minute each year in adults. Although the prevalence of sinus node dysfunction is unknown in the elderly, $70-80 \%$ of PMs for sinus node dysfunction are implanted over the age of 65 years; after that age, the prevalence of symptomatic sinus bradycardia is estimated at $1 / 600[20,21]$.

In the atrioventricular (AV) nodal region, normal ageing causes calcifications of the cardiac fibrous skeleton, which may lead to a slowing of conduction velocity in the AV node, the His bundle or the proximal part of the right and left bundle. Prolongation of the PR interval, which occurs with age, is well known $[20,21]$. In elderly subjects, $20 \%$ had a PR interval longer than $200 \mathrm{~ms}$ in the Manitoba Study [22], while it exceeded $220 \mathrm{~ms}$ in only $4 \%$ of the overall population. However, this study showed that the life expectancy of patients presenting with a prolonged PR interval was not impaired during the 30 years of follow-up, compared with subjects 
with normal AV conduction. In contrast, in an overview of the Framingham study [23], prolongation of the PR interval was correlated with a higher risk of atrial fibrillation (AF) and global mortality, even when the PR interval remained within the normal range.

Prevalence of type I second-degree AV block was reported to be $2.2 \%$ in an observational study involving 625 patients from various age groups (aged 22 to 80 years). Another study on 157 patients reported a PM implantation rate of $61 \%$ for type I second-degree AV block. During the 5 years after implantation, quality of life was improved in the youngest patients (aged 45 to 79 years), but not in those aged $>80$ years.

Ageing progressively affects the conduction capacity of the terminal part of the intraventricular conduction system [24]. The QRS duration remains stable. The mean frontal QRS axis shifts towards the left, so the prevalence of left axis deviation beyond $-30^{\circ}$ reaches $20 \%$ within the tenth decade. The prognosis value of this axis deviation is unknown. The prevalence of right bundle branch block increases with age, reaching its peak at the age of 70 years in men, but is still increasing at that age in women. In the Baltimore Longitudinal Study of Aging, the mean age at onset of right bundle branch block was $64 \pm 14$ years. The involvement of right bundle branch block in the onset of heart disease or in mortality seems poor. The incidence and prevalence of left bundle branch block also increases with age; in the Framingham study [25], its prevalence was $1.1 \%$, the mean age of occurrence was 62 years and, in the majority of the cases, it was associated with a known heart disease or preceded its development. In an Irish cohort study of 110,000 subjects followed between 1968 and 1993, the prevalence of left bundle branch block increased with age in both men and women [26]. AV blocks over type I second-degree affect elderly subjects, with or without heart disease [20,21]. The prevalence of third-degree AV block remains low. In the Reykjavik study [27], with a 24-year follow-up among 20,000 individuals, only 11 of them $(0.04 \%)$ had new-onset third-degree AV block.

It is thus not surprising that the mean age at PM implantation is 75 years, that $80 \%$ of the implanted patients are aged $>65$ years and that most patients receiving a PM for AV block are aged $>60$ years.

\section{Ventricular arrhythmias}

As with $\mathrm{HF}$, the incidence of heart rhythm disorders increases with age. In the aging man, the incidence of ventricular arrhythmias increases independent of the presence of underlying heart disease, but few detailed epidemiological data are available $[28,29]$.

\section{Ventricular premature beats}

Studies based on Holter electrocardiogram data in aging people showed the presence of premature ventricular beats (PVBs) in $77-100 \%$ of the patients, independent of the presence of underlying cardiomyopathy [30,31]. Sherman et al. found an exponential increase in PVBs with age: $17 \%$ before the age of 30 years; $29 \%$ between the ages of 30 and 60 years; and $75 \%$ over the age of 60 years [31]. Isolated PVBs are associated with a worse prognosis in case of underlying cardiomyopathy. Complex PVBs (non-sustained ventricular tachycardia [VT] or $>15 \mathrm{PVBs} /$ hour) were recorded in the Cardiovascular Health Study [32] in 16\% of women and $28 \%$ of men, and were generally associated with an underlying cardiomyopathy.

\section{Sustained ventricular arrhythmias}

The main aetiology of sustained VT in aging people is coronary artery disease; the second most frequent aetiology is dilated cardiomyopathy. In a French study by Raybaud et al., considering 202 patients aged $>75$ years admitted for VT, 22\% were ischaemic and 50\% were iatrogenic [30]. Bundle branch reentry is a rare cause of VT, but needs to be ruled out, as it is easily curable by right bundle branch ablation. A bundle branch reentrant ventricular has been shown to be inducible in $4.5-6 \%$ of patients with ischaemic cardiomyopathy, and in $17-40 \%$ of patients with dilated cardiomyopathy [33-35]. Torsades de pointe is a unique feature of dramatic concern in aging patients, which can result in sudden death; the main cause is iatrogenic QT prolongation, but it may also be secondary to excessive QT prolongation resulting from to AV block-associated bradycardia.

\section{Sudden death in older patients}

SCD may be related to malignant ventricular arrhythmias, with $62 \%$ monomorphic VT, $8 \%$ primary ventricular fibrillation and $17 \%$ secondary to bradycardias [36]. The leading cause is ischaemic (88\%), and the prognosis is poor in the elderly ( $<5 \%$ survival rate) [37]. In the few published studies about SCD in old people, age was a factor for poor prognosis. SCD in old people may be related mostly to electromechanical dissociation or asystole [38-40], which are associated with a $100 \%$ mortality rate in most studies. Symptoms preceding cardiac arrest may differ depending on age. Younger patients frequently complain about chest pain, although older patients report dyspnoea [40]. Independent of age, most patients with chest pain presentation before cardiac arrest have ventricular fibrillation, and patients with dyspnoea more frequently have electromechanical dissociation. Older survivors may exhibit cognitive or mood disorders, highlighting the influence of age after resuscitated SCD [41].

\section{Impact of comorbidities in patients needing ICD implantation}

\section{Cardiac evaluation}

Ischaemic, valvular or hypertensive heart diseases are more prevalent with increasing age, and may be complicated by HF during their evolution, which is the main indication for an ICD and/or CRT. Comorbidities, such as AF, peripheral vascular disease, diabetes, pulmonary disease, depression, anaemia and renal dysfunction, are prevalent in one form or another in many elderly patients scheduled for PM or ICD implantation [42]. A search for an extracardiac cause, such as bronchopneumonia, chronic obstructive pulmonary disease, pulmonary embolism or sleep apnoea syndrome, should often be carried out in the context of dyspnoea with suspected HF. The question of whether older patients with multiple comorbidities commonly seen in "real-world" 
clinical practice will benefit in terms of survival and quality of life from implantation of costly devices is discussed later. These issues are specifically relevant for patients for whom ICD implantation is being considered, and do not really apply to patients needing cardiac pacing or CRT.

The prevalence of $\mathrm{HF}$ is between $10 \%$ and $20 \%$ in those aged 70-80years [43], and increases by a factor of 10 between the ages of 60 and 80 years $[44,45]$. HF may be the reason (rather than a limitation or non-indication) for device implantation, unless life expectancy is estimated to be dramatically short. Although $50 \%$ of HF patients are aged $>75$ years, many clinical trials have included younger patients with a mean age of 61 years. Aging HF patients are more often women with less frequent cardiovascular disease and associated risk factors, but with more noncardiovascular comorbidities, such as chronic renal failure, anaemia or cancer [46-48]. In aging HF patients, 50\% exhibit preserved ejection fraction HF, the long-term prognosis of which is similar to that of HF with depressed ejection fraction [49]. Sudden death occurs 6 to 9 times more frequently in HF patients than in general population. High blood pressure and diabetes are stronger risk factors in aging women, and smoking and coronary heart disease are stronger risk factors in men [50].

Hypertension may be highly prevalent in PM recipients $[51,52]$, but high blood pressure is far less common in patients with severe systolic HF, which is the most common indication for an ICD and/or CRT. Excessively high or low blood pressure may be associated with a poor outcome in patients with coronary artery disease or HF. There may be a reverse association between baseline hypertension (actually protective) and mortality in elderly patients with HF or coronary artery disease [53,54]. However, blood pressure control in patients with a PM or ICD and hypertension is a relevant goal, in any case, for the prevention of complications, particularly cerebral strokes.

Diabetes commonly coexists, and is a powerful independent predictor of morbidity and mortality, in patients with $\mathrm{HF}$ [55]. Diabetes is not a predictor of poor response to CRT $[55,56]$, and diabetic HF patients treated with CRT seem to have an outcome that is similar to that of non-diabetic patients $[57,58]$. Diabetic patients derive a similar benefit from ICD therapy, despite being possibly sicker and having a higher mortality rate overall [59].

The prevalence of $\mathrm{AF}$ in patients with $\mathrm{HF}$ ranges from $5 \%$ in patients with New York Heart Association (NYHA) functional class I to $40 \%$ in patients with NYHA class IV, and increases markedly with age [60]. AF may be associated with a higher risk of cardiac events and mortality in population studies, but should not per se affect the decision to implant a device at an individual level in the elderly; it may, however, influence the type of the device and its programming. AF patients show significant improvement after CRT, with improvements in left ventricular (LV) ejection fraction that are similar to or slightly greater than those in patients in sinus rhythm [61]. In patients treated with CRT with defibrillation (CRT-D), history of AF is an independent risk factor, not only for mortality, but also for appropriate and inappropriate shocks [62]. Compared with patients with permanent $A F$, those with paroxysmal or persistent AF may have a lower increase in the risk of mortality or appropriate device therapy, but a higher risk of inappropriate device therapy [63].
Further efforts in AF management may thus optimize the care in elderly patients with electric cardiac devices.

Renal dysfunction is a common comorbidity in HF in the elderly, and is individually associated with poorer outcomes $[64,65]$. Renal impairment does not prevent a positive response to CRT, even in elderly patients [56]. CRT might actually be a renal-protective strategy in HF, and improvement in renal function can be another mechanism to explain the beneficial effects of CRT $[66,67]$.

Importantly, comorbid conditions, such as renal failure, NYHA stage IV HF, AF or third-degree heart block, are stronger predictors than age in determining higher risk of peri- and post-procedural complications [68]. Elderly patients with comorbidities, but with a good life expectancy, may benefit from pacing, CRT or ICD, although "reasonable expectation of survival" has not been standardized. Koplan et al. found that a proportion of patients aged $>80$ years may survive for $\geq 4$ years after ICD implantation, despite comorbidities, and survival may reach 6 years for those with an ejection fraction $>30 \%$ and a glomerular filtration rate $>60 \mathrm{~mL} / \mathrm{min}$, while the overall life expectancy of octogenarians in the USA is 8 years [69]. Goldenberg et al. developed a simple risk model with five clinical factors (NYHA functional class $>1 \mathrm{I}$, age $>70$ years, blood urea nitrogen $>26 \mathrm{mg} / \mathrm{dL}$, QRS duration $>0.12$ seconds and $A F$ ) for ICD recipients with low ejection fraction. The authors found a pronounced benefit for ICDs in terms of risk of death in intermediate-risk patients, and attenuated efficacy in lower-risk patients ( 0 risk factors) and higher-risk patients [65]. Thus, comorbidities should certainly be considered when determining whether an elderly patient will markedly benefit from a device or not. Other non-cardiac conditions, such as peripheral vascular disease or pulmonary disease, may have a negative effect on survival in ICD recipients [70]; this could influence the decision regarding which device to implant (see section entitled "CRT-P or CRT-D?").

\section{Geriatric assessment}

An evaluation before the implantation of an ICD in an elderly person should be accompanied by a geriatric assessment that gauges the person's overall prognosis, with psychosocial and medical assessments (comorbidities, autonomy). It is necessary to determine the patient's condition to know whether the person will benefit from the implantation of an ICD in terms of functional capabilities, but also to attempt to predict whether this condition will be maintained over the coming months or semesters or, on the contrary, whether the patient is at risk of deteriorating. The "Comprehensive Geriatric Assessment"' (CGA) [71] assesses a person's state of health, and provides information on functional status, continuing to live at home and overall survival [72]. However, the CGA requires a certain expertise in geriatrics that takes time (mobile geriatric team, day hospital, geriatric care networks) and cannot be offered to all patients (Table 1). Several tools can be used to screen for patients who should undergo a CGA, including the Identification of Seniors at Risk score, the Triage Risk Screening Tool and the G-8.

The French National Authority for Health (Haute Autorité de santé) $[73,74]$ has proposed the presence of the following as factors in decision-making: a "geriatric syndrome" (undernutrition, depression, falls, mental 
Table 1 Areas explored by the Comprehensive Geriatric Assessment, and interventions within the framework of the Personalized Care Plan.

\begin{tabular}{|c|c|}
\hline $\begin{array}{l}\text { Area to be } \\
\text { explored }\end{array}$ & Interventions \\
\hline \multirow{2}{*}{$\begin{array}{l}\text { Diagnostic and } \\
\text { therapeutic } \\
\text { optimization }\end{array}$} & Assess and manage comorbidities \\
\hline & $\begin{array}{l}\text { Review medications and their } \\
\text { risk-benefit ratios, and review } \\
\text { dosage and adapt it to kidney } \\
\text { function }\end{array}$ \\
\hline \multirow{3}{*}{$\begin{array}{l}\text { Cognitive } \\
\text { impairment }\end{array}$} & Specific treatments if needed \\
\hline & Home help if needed \\
\hline & $\begin{array}{l}\text { Discuss the suitability of the } \\
\text { intervention depending on the } \\
\text { severity of the impairment }\end{array}$ \\
\hline \multirow[t]{2}{*}{ Depression } & Antidepressant treatments \\
\hline & $\begin{array}{l}\text { Discuss the suitability of the } \\
\text { intervention depending on the } \\
\text { severity of the impairment }\end{array}$ \\
\hline \multirow[t]{3}{*}{ Undernutrition } & Nutritional fortification \\
\hline & Oral nutritional supplements \\
\hline & $\begin{array}{l}\text { Discuss the suitability of the } \\
\text { intervention depending on the } \\
\text { severity of the impairment }\end{array}$ \\
\hline \multirow{4}{*}{$\begin{array}{l}\text { Difficulty } \\
\text { walking, falls }\end{array}$} & Aetiological evaluation \\
\hline & Physiotherapy \\
\hline & Adapted physical activity \\
\hline & $\begin{array}{l}\text { Discuss the suitability of the } \\
\text { intervention depending on the } \\
\text { severity of the impairment }\end{array}$ \\
\hline \multirow[t]{3}{*}{ Loss of autonomy } & Home help \\
\hline & $\begin{array}{l}\text { Plan post-intervention follow-up } \\
\text { and rehabilitation care }\end{array}$ \\
\hline & $\begin{array}{l}\text { Discuss the suitability of the } \\
\text { intervention depending on the } \\
\text { severity of the impairment }\end{array}$ \\
\hline Isolation & Home help \\
\hline
\end{tabular}

confusion, pressure ulcers); a loss of autonomy existing before hospitalization, based on abnormality in at least one activity of daily living (Activities of Daily Living [ADL] index [75]; personal hygiene, bathing, dressing, continence, going to the toilet, transferring, feeding; Appendix 1); a history of an unplanned hospitalization in the last 6 months; and an unfavourable social situation (precariousness, isolation).

The Haute Autorité de santé has also proposed a score for identifying at-risk individuals, namely the Triage Risk Screening Tool [76], which can be done in a few minutes by a non-physician and comprises five items: cognitive impairment; difficulty with walking/transferring or recent falls; polymedication (five or more medications per day); history of hospitalization in the last 90 days or admission to an emergency department in the last 30 days; and abnormality before hospitalization in at least one activity of daily living (ADL index) or social isolation.
The cardiology team can detect the main "geriatric syndromes" that should be the subject of a geriatric assessment and more complete treatment if abnormality is detected.

\section{Cognitive impairment}

Identifying cognitive impairment can involve the MiniMental State Examination or a simpler test, such as the Memory Impairment Screen [77]. The Mini-Mental State Examination [78] has a score range of 30; the threshold value depends on age and sociocultural level. A score of $<27$ points hints at possible cognitive impairment; a score of $<24$ points hints at possible dementia and warrants a specialized assessment. The Memory Impairment Screen [79] consists of having an individual repeat four words written on a sheet of paper (e.g. CHECKERS, SAUCER, TELEGRAM and RED CROSS) immediately and 10 minutes later. Forgetting one of the words (despite a clue, e.g. "What was the name of the game?") hints at cognitive impairment and calls for a specialized complementary assessment. Other tests (such as the CODEX tests, the five-word test, the clock test, etc.) can be used to detect cognitive impairment.

\section{Risk of falls}

Assessing the risk of falls involves a series of questions (relating to previous falls), a clinical examination (general condition, neuromuscular status, joints, vision and neurological and cardiovascular examinations, looking in particular for orthostatic hypotension) and a few simple tests, such as the stand-on-one-leg test, which assesses an individual's ability to remain standing on one leg for 5 seconds, and the Timed Up and Go test, which assesses balance and gait (the elderly person must get up from a chair with armrests, walk 3 meters in a straight line to a line drawn on the ground, turn around and sit back down again, with a time of $>20$ seconds indicating a risk of falls).

\section{Undernutrition}

Undernutrition is defined as weight loss $>5 \%$ in 1 month or $>10 \%$ in 6 months, and signals the presence of a risk situation. Weight should be interpreted taking into account clinical and biological factors of water retention and dehydration. A nutritional assessment can also be done by determining serum albumin; a value of $<35 \mathrm{~g} / \mathrm{L}$ indicates undernutrition. Treatment of undernutrition can improve life expectancy.

\section{Depression}

The "Mini Geriatric Depression Scale" (Appendix 2) is a quick four-question screening test. If abnormality is detected, the full GDS scale gathers depressive symptoms. A score $>15 / 30$ indicates the possibility of depression, and a score $>22 / 30$ indicates the possibility of major depression. Depression is associated with a more severe cardiovascular prognosis and poorer treatment adherence in the elderly [80]. 


\section{Frailty}

Detecting frailty (a syndrome of deterioration of physiological reserves and decreased resistance to stress) should also be part of the assessment, as it is associated with unfavourable developments after implantation $[81,82]$. The Gérontopôle Frailty Screening Tool [83] in individuals with an $A D L$ score $\geq 5 / 6$ includes six items: living alone; involuntary weight loss in the last 3 months; fatigability in the last 3 months; mobility difficulties in the last 3 months; memory complaints; and slow gait speed (more than 4 seconds to walk 4 meters).

\section{Autonomy}

Autonomy can be evaluated by scales that assess activities of daily life (Instrumental ADL and ADL) through questioning the patient and their relatives. The short form of the Instrumental ADL scale includes four items: ability to use the telephone; ability to use transport; responsibility for own medication; and ability to handle finances. The ADL scale gives information about personal hygiene and grooming, dressing, ability to go to the toilet, transferring, continence and ability to eat alone. A subject is considered dependent if they need human help to carry out the activity concerned.

\section{Lifestyle}

The assessment should determine the patient's state of isolation, and take into account the involvement of caregivers (family members or friends) and access to different care services; this includes providing disease information and education to the patient and those close to the patient, to ensure that medications are taken and to attend to complications early.

Thus, the CGA allows a Personalized Care Plan to be prepared before and after intervention, within the framework of a multiprofessional approach (Fig. 1).

\section{Cardiac pacing}

\section{Choice among devices with different pacing modes for older patients}

The choice of optimal pacing mode for older patients is under debate, as is whether VVI pacing should be preferred for cost reduction (including patients with preserved sinus node function) or whether physiological pacing should be favoured. The choice of pacing mode varies, depending on the disorder to treat (sinus node dysfunction, acquired AV block or permanent AF associated with bradycardia); it also depends on whether bradycardia is paroxysmal or permanent. The 2013 European professional practice recommendations do not specifically discuss age, while the majority of paced patients are now in an older age bracket [84].

A survival benefit conferred by DDD instead of singlechamber pacing is controversial. DDD pacing may limit the risk of developing AF, stroke or HF. Older studies have compared DDD with AAl pacing, a mode that is rarely used nowadays, having been mostly replaced by algorithms to preserve AV conduction. In a 1997 Danish study, 225 patients (mean age, 71 years) were randomly assigned to $\mathrm{VVI}$ versus AAl pacing for sick sinus syndrome, and were followed for up to 8 years [85]. Atrial pacing was associated with longer survival, a shorter duration of AF, less HF and fewer thromboembolic events. In PASE, a study of patients whose mean age was 76 years, the superiority of DDD compared with AAI pacing was mostly confined to patients paced for sinus node dysfunction, and was not significant in cases of AV block [86]. The MOST study compared VVI with DDD pacing in 2010 patients with sinus node dysfunction (mean age, 74 years) [87]. DDD pacing lowered the risk of AF and HF, and improved the quality of life, but did not lower the risk of stroke. The devices had to be reprogrammed from VVI to DDD mode in $20 \%$ of patients because of disabling PM syndrome [88]. The CTOPP study enrolled patients with a mean age of 73 years, who presented with a mix of AV block and sinus node dysfunction [89]. Over a follow-up period of more than 6 years, the risk of $A F$ was decreased, but not the risk of death or stroke. In the UK PACE study, 2021 patients aged $>70$ years underwent implantation of PMs for AV block, and were randomly assigned to VVI versus DDD pacing $[90,91]$. During a follow-up period of up to 5 years, no difference in mortality was observed between the two study groups, and no difference was seen in the development of AF, HF or stroke. In none of these older studies was an algorithm available to preserve AV conduction.

Chao et al. compared 108 PM recipients aged $>90$ years with a matched non-paced control group [92]. Cardiac pacing was not associated with a higher mortality, confirming that very old age is not a contraindication to PM implantation. Antonelli et al. studied VVI pacing in nonagenarians over a period of more than 20 years, and observed no adverse effect on survival [93].

In summary, in older patients with sinus node dysfunction, experts agree that DDD pacing along with the programming of an algorithm to minimize ventricular pacing (see section entitled "Specific algorithms to decrease the percentage of ventricular pacing") is preferred [84]. Rate responsiveness may be helpful in the elderly, and should be added in cases of sinus node dysfunction associated with chronotropic incompetence. Permanent AV block and no permanent AF should be treated with DDD pacing because of the risk of PM syndrome, which develops in $20 \%$ of patients. In very old patients presenting with intermittent AV block or syncope and suspected AV block, VVI pacing may be all that is needed. $\mathrm{VVI}$ pacing is also preferred to treat AF associated with bradycardia. These patients may, in the future, be candidates for leadless pacing, broadening the indications for VVIR pacing.

\section{Choice of pacing site}

Ventricular pacing cannot be avoided or minimized in patients with permanent complete heart block. Right ventricular (RV) apical pacing is the most common site of lead positioning in the majority of patients receiving PMs, because of the direct access during implantation. Several large randomized clinical trials have demonstrated a direct association between a high percentage of RV apical pacing and a worse clinical outcome; this prompted the development of specific algorithms to decrease unnecessary 


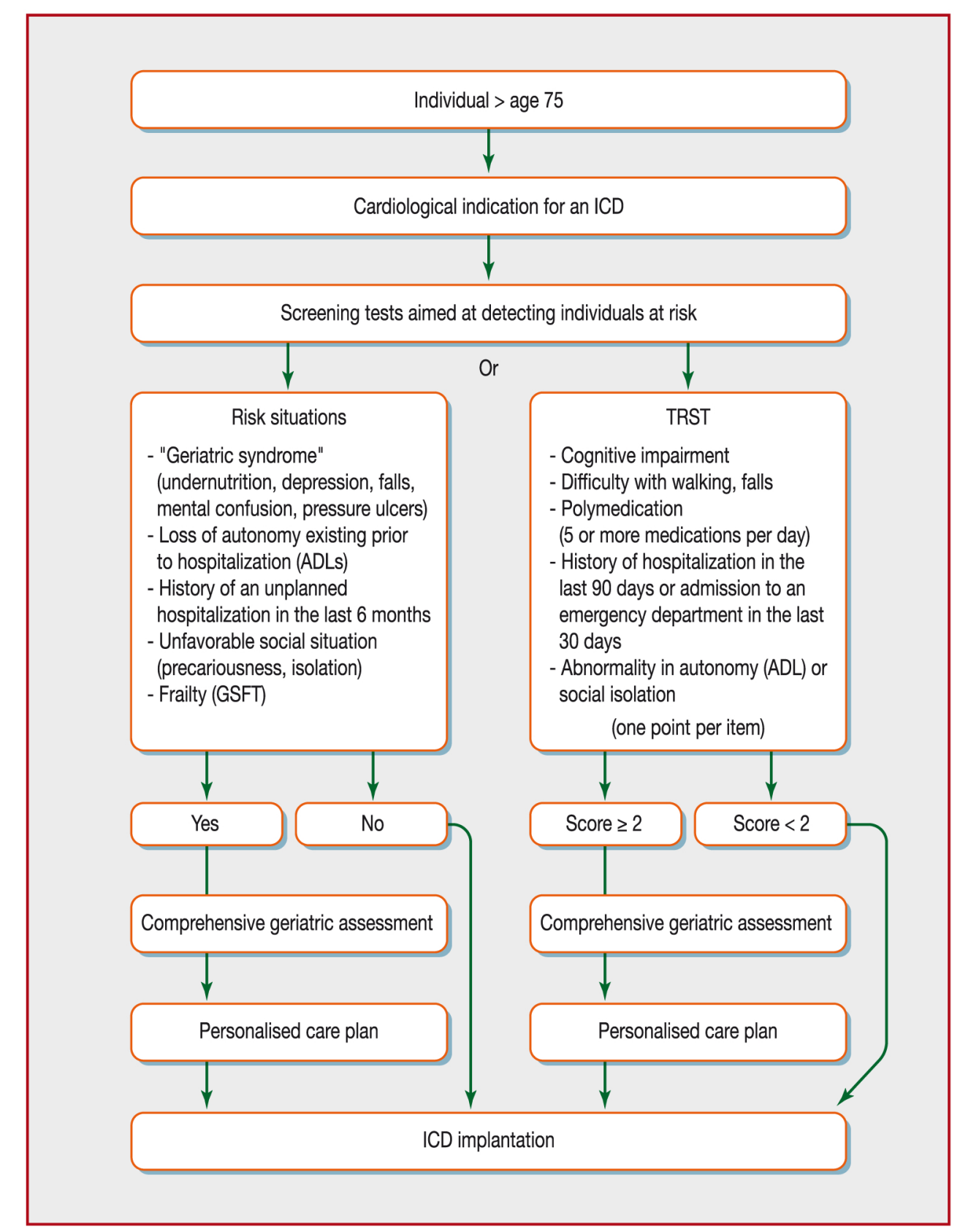

Figure 1. Course of care before an implantable cardioverter defibrillator (ICD) after the age of 75 years. ADL: activities of daily living; GFST: Gérontopôle Frailty Screening Tool; TRST: Triage Risk Screening Tool.

RV pacing (see section entitled "Specific algorithms to decrease the percentage of ventricular pacing") and search for alternative pacing sites when pacing is inevitable [94-96]. Furthermore, apical positioning may be associated with a higher risk of perforation, particularly in old and thin women.

The septum, the RV outflow tract and the His bundle have been suggested as alternative pacing sites to the RV apex. Because of the closer proximity to the normal conduction system, these RV sites may result in less electromechanical dyssynchrony and a more physiological activation. However, whether there is an optimal site for RV pacing remains controversial. A randomized study comparing outflow tract pacing and RV apical pacing failed to show sustained additional clinical benefit $[97,98]$. Direct $\mathrm{His}$ pacing may, theoretically, be an attractive alternative, but feasibility may be limited [99]. Therefore, the potential benefits of alternative RV pacing sites in old patients remain unclear. The level of proof for systematic implantation of a biventricular device in old patients with complete AV block also remains too limited for this to be proposed in clinical practice.

\section{PM programming in the elderly}

\section{Rate programming and modulation}

Rate response has been compared with non-response (ventricular and atrial) pacing in patients with bradycardia in several randomized trials [100-104]. While there is evidence of superiority of VVIR over VVI pacing, in terms of 
improving quality of life and exercise capacity, improvements in exercise capacity with DDDR compared with DDD have been conflicting. In two small studies of patients with chronotropic incompetence $[103,104]$ comparing DDD and DDDR pacing, the latter improved quality of life and exercise capacity, but the larger ADEPT randomized trial [100] failed to show a difference in patients with a bradycardia indication for DDD pacing.

The upper rate limit should be programmed higher than the fastest spontaneous sinus rhythm to avoid upper rate limit behaviour. The lower rate should be programmed on an individual basis in the elderly patient, according to the clinical characteristics and the underlying cardiac substrate of the patient, to avoid symptomatic bradycardia.

\section{Specific algorithms to decrease the}

\section{percentage of ventricular pacing}

With the increasing evidence of the detrimental effects of RV apical pacing, the percentage of ventricular pacing should be kept to a minimum in patients with sinus node dysfunction or intermittent AV block. Unnecessary RV pacing may induce AF and deterioration of HF $[95,96]$. Percent ventricular pacing is, therefore, an important aspect of the follow-up of old patients with sinus node dysfunction, with a view to maximally decreasing unnecessary ventricular pacing. The most reliable strategy is to avoid implanting a ventricular lead. However, the adoption of DDD systems as the standard of care has prompted the development of proprietary algorithms that promote normal $\mathrm{AV}$ conduction and minimize unnecessary RV pacing $[94,95]$. These algorithms may lower considerably the percentage of ventricular pacing, without jeopardizing patient safety, and may significantly extend the longevity of the PM. The algorithms may decrease the number of hospitalizations and deaths from cardiac causes, although they do not clearly lower the risk of $\mathrm{AF}$ and $\mathrm{HF}$, or the need for cardioversion $[94,95]$. It is important, however, when programmable, not to accept prolonged ventricular pause ( $>2$ seconds) that may lead to the occurrence of syncope in old and fragile patients.

\section{Magnetic resonance imaging (MRI) compatibility}

After implantation, a substantial proportion of elderly patients with a PM may develop an indication for MRI examination because of medical comorbidities [105]. Implantation of MRI-conditional devices is today becoming a standard of care. Recommendations have been published on how to perform an MRI examination securely in patients with conventional devices or MRI-conditional PM systems [84]. It actually appears that MRI in patients with MRI-conditional pacing systems and selected patients with MRI-unsafe systems can be performed safely under strict conditions in daily clinical practice [106].

\section{ICDs}

ICDs in patients at high risk of SCD have been associated with a decrease in overall mortality, thanks to a significant reduction in arrhythmic death [1-7]. ICD devices are generally implanted in highly selected patients, presenting few comorbidities, with a limited proportion of old patients aged $>75$ years $[1,6,18,107]$; a minority of those deemed eligible for ICD implantation are octogenarians [10]. The number of elderly patients being considered for ICD implantation is increasing, but the relative contribution of non-arrhythmic mortality in the elderly may also confound the benefits of ICD therapy $[10,70,108]$. In the absence of specific randomized trial data, the benefit of ICDs still remains controversial in elderly patients. However, guidelines do not refer to specific age limits, but rather to 1-year life expectancy as a mandatory criterion [18].

\section{Is the risk/benefit balance globally positive in elderly patients?}

The first question is: "Is ICD implantation more risky in elderly patients?". Many trials have evaluated the risk of operative or perioperative complications in elderly patients (Table 2). Among 150,264 primary prevention ICD recipients, the occurrence of any adverse event or in-hospital death increased from $2.8 \%$ in the youngest age group ( $<65$ years) to $4.5 \%$ in the oldest age group ( $\geq 80$ years) [68]. Comorbidities, such as severe HF, chronic kidney disease, AF or advanced heart block, were stronger predictors than age in determining complication risks. ICD implantation by non-electrophysiologists or less experienced operators was more significant in predicting complications than age [68]. Many studies reported similar rates of procedure-related complications or long-term complications between different age groups (including infection, lead failure and lead dislodgement) [17,109-114]. By contrast, several publications found that early complications were increased in elderly patients, ranging from $<10 \%$ to $17 \%$ [115-117]. More frequent comorbidities may explain this finding.

In elderly patients referred for ICD implantation, a simple risk score consisting of 10 available variables can accurately identify patients at high and low risk of complications [118]. Interestingly, age $>80$ years has recently been associated with a significant reduction in complication risk, mostly as a result of a marked reduction in the frequency of lead-related reinterventions [119].

ICD implantation in the elderly: pros and cons Evidence supporting ICD implantation in the elderly [14]

Chan et al. showed that ICD therapy in primary prevention was associated with similar absolute and relative mortality risk reductions in elderly patients, despite higher annual mortality rates [13]. Combining data from major randomized control trials, Kong et al. reported that primary prevention ICD therapy remained effective in reducing all-cause mortality in patients aged $\geq 75$ years [17], contradicting a similar meta-analysis published 1 year before [19].

\section{Evidence against ICD implantation in the elderly}

Because the median survival of elderly patients with an ICD has been shown to be $<5$ years in most studies $[69,114,120,121]$, the effectiveness of the ICD in prolonging life expectancy seems marginal. The benefit of the ICD in the primary prevention of SCD, according to the MADIT-II and SCD-HeFT trials, emerged only in a mid- to long-term 
Table 2 Studies evaluating the risk of complications after implantable cardioverter defibrillator implantation in the elderly (adapted from Barra et al. [134]).

\begin{tabular}{|c|c|c|}
\hline Study & Population & Findings \\
\hline Tsai et al. [68] & $\begin{array}{l}\text { Primary prevention ICD } \\
\text { recipients in the USA } \\
\text { NCDR ICD Registry; } \\
150,264 \text { patients }(61 \% \\
\text { aged } \geq 65 \text { years; } 16.1 \% \\
\text { aged } \geq 80 \text { years) }\end{array}$ & $\begin{array}{l}\text { Occurrence of any periprocedural adverse event or in-hospital } \\
\text { death increased from } 2.8 \% \text { in the youngest age group ( }<65 \text { years) } \\
\text { to } 4.5 \% \text { in the oldest age group ( } \geq 80 \text { years); renal failure, stage } \\
\text { IV heart failure, atrial fibrillation, third-degree heart block, } \\
\text { biventricular ICD placement, female sex, physician } \\
\text { non-certification and device implantation by } \\
\text { non-electrophysiologists were stronger predictors of } \\
\text { complications than age }\end{array}$ \\
\hline Grimm et al. [111] & $\begin{array}{l}500 \text { consecutive } \\
\text { patients included in the } \\
\text { Marburg Defibrillator } \\
\text { Database }\end{array}$ & $\begin{array}{l}\text { All procedure-related, lead-related and pulse generator-related } \\
\text { complications were similar in both patient groups ( } 23 \% \text { vs. } 25 \% \text { ) } \\
\text { during follow-up of } 48 \pm 39 \text { months }\end{array}$ \\
\hline Duray et al. [110] & $\begin{array}{l}375 \text { consecutive ICD } \\
\text { recipients with } \\
\text { structural heart disease }\end{array}$ & $\begin{array}{l}\text { Device associated complications were similar in both groups } \\
\text { (age }<70 \text { vs. } \geq 70 \text { years) }\end{array}$ \\
\hline Van Rees et al. [114] & $\begin{array}{l}1395 \text { patients treated } \\
\text { with a primary } \\
\text { prevention ICD }\end{array}$ & $\begin{array}{l}\text { Lower rate of inappropriate shocks in patients aged } \geq 75 \text { years; } \\
\text { similar rates of different complications, such as infection, lead } \\
\text { failure and lead dislodgment in elderly patients (aged } \geq 75 \text { years) } \\
\text { versus the other subgroups }\end{array}$ \\
\hline Reynolds et al. [113] & $\begin{array}{l}31,000 \text { Medicare } \\
\text { beneficiaries receiving } \\
\text { ICDs in } 2002-2003\end{array}$ & $\begin{array}{l}\text { Rate of one or more in-hospital complications related to ICD } \\
\text { implantation was } 10.8 \% \text {; age distribution was similar among } \\
\text { patients who did and did not experience complications }\end{array}$ \\
\hline Al-Khatib et al. [109] & $\begin{array}{l}8581 \text { patients } \\
\text { aged } \geq 65 \text { years, who } \\
\text { received an ICD } \\
\text { between January } 2002 \\
\text { and September } 2005\end{array}$ & $\begin{array}{l}\text { Age was not an independent risk factor for increased } \\
\text { complications }\end{array}$ \\
\hline Noseworthy et al. [112] & $\begin{array}{l}183 \text { septuagenarian ICD } \\
\text { recipients vs. } 29 \\
\text { octogenarians }\end{array}$ & $\begin{array}{l}\text { The complication rates at the time of ICD implantation were } \\
6.6 \% \text { in septuagenarians and } 13.1 \% \text { in octogenarians, but the } \\
\text { difference was not statistically significant }\end{array}$ \\
\hline Fauchier et al. [115] & $\begin{array}{l}\text { French registry of } 5534 \\
\text { primary prevention ICD } \\
\text { recipients }\end{array}$ & $\begin{array}{l}\text { Older age was independently associated with a higher rate of } \\
\text { early complications and a lower rate of inappropriate therapies }\end{array}$ \\
\hline Yung et al. [117] & $\begin{array}{l}\text { Registry of } 5399 \text { ICD } \\
\text { recipients in Ontario, } \\
\text { Canada }\end{array}$ & $\begin{array}{l}\text { Rates of complications within } 45 \text { days of implantation: aged } \\
18-49 \text { years, } 7.5 \% \text {; aged } 70-79 \text { years, } 7.6 \% \text {; aged } \geq 80 \text { years, } \\
10.7 \% \text { ( } P \text { not significant) }\end{array}$ \\
\hline
\end{tabular}

follow-up ( $2-5$ years). A meta-analysis on pooled data from the DEFINITE, SCD-HeFT and MADIT trials was unable to demonstrate significant survival benefit for the ICD in the elderly [19]. In the secondary prevention setting, a pooled analysis of individual patient data from the AVID, CIDS and CASH trials concluded that ICD therapy did not seem to provide a survival benefit in patients aged $\geq 75$ years [15]. Finally, the AVID trial showed an unadjusted average of only 2.7 months of additional life gained at 3 years in a cohort of patients with a mean age of 65 years [18].

\section{Primary prevention indications in elderly patients}

Current guidelines suggest that ICD therapy should be considered in the elderly as an efficient intervention to prevent
SCD when their life expectancy is acceptable [18]. Many randomized studies have reported divergent results regarding the benefit of ICDs in the elderly $[1,16,19,122]$. Because of the under-representation of elderly patients in randomized trials, observational studies with small samples in single centres and national registries investigated the efficacy of ICD in elderly patients and, similarly, yielded inconsistent results $[111,117,123,124]$. Recently, one of the largest longitudinal registries of ICD implantation for primary prevention of SCD in a "real life" French cohort of elderly patients, with an age-stratified analysis, suggested a similar benefit in those patients concerning the risk of SCD: older patients exhibited higher global mortality, whereas the rates of SCD and appropriate device therapies were similar for the different age groups [115].

In the MADIT-II trial, the risk of overall mortality in older patients in the ICD therapy group (compared with those in 
the conventional therapy group) was similar to the benefit observed in younger patients [16]. Lee et al. found that survival after ICD implantation was inversely related to the number of comorbidities [116], while the MADIT-II investigators suggested that ICD efficacy for primary prevention in ischaemic cardiomyopathy was U-shaped, with a lower benefit in the lowest-risk and highest-risk subgroups [65]. Consideration of comorbidities would thus help to identify elderly patients most likely to derive benefit from an ICD. A risk stratification, using the Multicenter Unsustained Tachycardia Trial (MUSTT) data set, found that NYHA class, conduction disturbance, decreased LV ejection fraction and $\mathrm{AF}$, all of which are likely to be more common in the elderly, were all associated with a higher mortality [125]. Those patients at highest risk of mortality would derive little benefit from the ICD [126].

While an annualized inappropriate shock rate reaching $24 \%$ over 3 years was previously reported, it ranges from $1 \%$ to $3 \%$ per year in the latest studies $[115,117,127,128]$; this may be related to different programming in primary prevention ICD in recent years, avoiding unnecessary therapies (see section entitled "Tachycardia detection and therapy programming in elderly patients"') [129-132]. Misdiagnosis of supraventricular tachycardia has accounted for many inappropriate ICD shocks $[127,128]$. However, the higher incidence of $\mathrm{AF}$ in the elderly population does not result in a greater number of inappropriate ICD shocks compared with younger patients. There are commonly a higher number of inappropriate shocks in younger patients, probably as a result of more frequent sinus tachycardia or lead failure with higher physical activity $[115,128]$.

In well-selected elderly patients at high risk of arrhythmic death and with few comorbidity factors despite advanced age, ICD intervention may reduce mortality to nearly age-specific life expectancy. Therefore, biological age, possibly assessed by a multivariable score (rather than chronological age per se), and individualized consideration, focusing on comorbidities, projected expectancy, quality of life and patient preference, should help in making a decision about ICD selection for survival benefit (Fig. 1).

\section{Secondary prevention indications in elderly patients}

One in five patients is implanted with an ICD in a secondary prevention setting [133]. In old patients, the decision to implant an ICD should be easier in secondary than primary prevention. After rescue of a SCD by ventricular fibrillation, or hospitalization for poorly tolerated VT, ICD implantation is obviously indicated, except in patients with a poor shortterm prognosis for another reason (terminal HF, advanced cancer). However, one should have a fair discussion with elderly patients about prognosis, the beneficial effect of the $I C D$, the adverse effects and the potential to convert a SCD to a non-sudden death for an appropriate shared decision. Life expectancy, comorbidities (i.e. other causes of death) and quality of life issues should then be addressed before ICD implantation. In scientific guidelines, ICD implantation for secondary prevention is recommended for patients with a reasonable expectation of survival with a good functional status for $>1$ year. This may seem restrictive, and the decision should be contextualized. The limit of 1 year is mainly based on the absence of benefit from an ICD seen before 9-12 months in primary prevention studies $[1,6]$.

Secondary prevention studies including patients with a mean age of 65 years have demonstrated a decrease in total mortality of around $28 \%$ with ICDs [3,4,7]. In the AVID trial, 9 patients had to be treated to save a life over a period of 3 years $[7,18]$. However, a meta-analysis suggested that ICD therapy did not show any survival benefit in patients aged $>75$ years [15]. In "real life", observed through registries and databases, elderly patients (aged $>80$ years) accounted for fewer than $10 \%$ of patients implanted with an ICD. In the Ontario ICD database [117], an annual mortality rate of $7 \%$ was observed in secondary prevention patients, with an appropriate shock rate of $12 \%$, both rates being lower than those reported in randomized studies; $8 \%$ of the patients in secondary prevention were aged $\geq 80$ years. The rate of all-cause death was high (annual mortality of $15.5 \%)$ in these patients. Most of the elderly patients survived $>30$ days after the shock, refuting the argument that elderly patients are more susceptible to unsuccessful shocks or electromechanical dissociation. Early complications were not increased in elderly patients. As for primary prevention ICDs, older age does not diminish the likelihood of receiving appropriate therapy, but a careful evaluation of comorbidities that may increase the relative risk of non-arrhythmic mortality is needed.

\section{Tachycardia detection and therapy programming in elderly patients}

The mean age of patients included in initial ICD studies was $60-65$ years [134]. Less than $25 \%$ of subjects included in the major clinical trials were estimated to be aged $>75$ years. Historical studies even purposely excluded patients aged $>80$ years $[6,135,136]$. Hence, prospective historical trials may not be representative of daily clinical practice. On the other hand, recent studies have studied the efficacy of prespecified ICD programming parameters in patients with few or no exclusion criteria [130-132,137-139]. These studies focused on new programming strategies to decrease the rate of inappropriate therapies and deliver less aggressive therapy in case of sustained ventricular arrhythmia. Whether such modern strategies are both safe and efficient in elderly patients (i.e. aged $>75$ years) is an open question, but concordant conclusions can be made from these studies. Prolonged detection as well as high ventricular fibrillation rates decrease the number of inappropriate therapies and the number of shocks with the use of antitachycardia pacing (instead of painful shocks) in fast VT (Table 3). In primary and secondary prevention patients, long detection can be safely programmed even in elderly patients. Such programming parameters are recommended in current consensus documents proposed by scientific societies [140], and may be safely applied in elderly patients.

\section{HF management with CRT}

CRT is now considered as a key therapeutic option in drug-refractory HF patients with low LV ejection 
Table 3 Main evidence for tachycardia detection and therapy programming in patients with an implantable cardioverter defibrillator.

\begin{tabular}{|c|c|c|c|c|c|}
\hline Study & Participants & Age & Controls & Intervention & Findings \\
\hline PREPARE [132] & $\begin{array}{l}n=1391 ; \text { primary } \\
\text { prevention; } \\
\text { non-randomized }\end{array}$ & $\begin{array}{l}67 \pm 12 \text { years (no } \\
\text { upper age limit) } \\
\text { in PREPARE group } \\
\text { vs. } 66 \pm 12 \text { years } \\
\text { in controls }\end{array}$ & $\begin{array}{l}\text { Short detection: } \\
12 \text { of } 16(58 \%) ; 18 \\
\text { of } 24(42 \%)\end{array}$ & $\begin{array}{l}\text { Prolonged } \\
\text { detection: } 30 \text { of } \\
40\end{array}$ & $\begin{array}{l}290 \text { lightheaded or } \\
\text { syncopal adverse } \\
\text { events ( } 41 \%) \text { in the } \\
\text { PREPARE group, } \\
\text { among which } 31 \\
\text { (11\%) were related } \\
\text { to arrhythmia; 50\% } \\
\text { judged to be } \\
\text { specifically related } \\
\text { to the PREPARE } \\
\text { programming } \\
\text { parameters, but not } \\
\text { to increased age; } \\
\text { reduction in } \\
\text { inappropriate shocks } \\
\text { (SVT), avoidable } \\
\text { shocks (VT) and } \\
\text { "morbidity index", }\end{array}$ \\
\hline $\begin{array}{l}\text { RELEVANT } \\
\text { [137] }\end{array}$ & $\begin{array}{l}n=324 ; \text { primary } \\
\text { prevention; } \\
\text { non-randomized }\end{array}$ & $\begin{array}{l}64 \pm 12 \text { years (no } \\
\text { upper age limit) }\end{array}$ & $\begin{array}{l}\text { Short detection: } \\
12 \text { of } 16\end{array}$ & $\begin{array}{l}\text { Prolonged } \\
\text { detection: } 30 \text { of } \\
40\end{array}$ & $\begin{array}{l}\text { Reduction in } \\
\text { inappropriate shocks } \\
\text { (SVT), avoidable } \\
\text { shocks (VT) and HF } \\
\text { hospitalizations }\end{array}$ \\
\hline $\begin{array}{c}\text { MADIT-RIT } \\
\text { [131] }\end{array}$ & $\begin{array}{l}n=1500 ; \text { primary } \\
\text { prevention; } \\
\text { randomized }\end{array}$ & $\begin{array}{l}63 \pm 12 \text { years (no } \\
\text { upper age limit) }\end{array}$ & $\begin{array}{l}\text { Short detection: } \\
2.5 \text { seconds } \\
(170-199 \mathrm{bpm}) ; 1 \\
\text { second } \\
(\geq 200 \mathrm{bpm})\end{array}$ & $\begin{array}{l}\text { Prolonged } \\
\text { detection: } \\
60 \text { seconds } \\
(170-199 \mathrm{bpm}) \\
12 \text { seconds } \\
(200-249 \mathrm{bpm}) \\
2.5 \text { seconds } \\
\text { ( } \geq 200 \mathrm{bpm})\end{array}$ & $\begin{array}{l}\text { Reduction in first } \\
\text { inappropriate } \\
\text { therapy, first } \\
\text { appropriate therapy, } \\
\text { appropriate ATP and } \\
\text { inappropriate ATP; } \\
\text { improved survival }\end{array}$ \\
\hline $\begin{array}{l}\text { ADVANCE-III } \\
\text { [130] }\end{array}$ & $\begin{array}{l}n=1902 ; \text { primary } \\
\text { or secondary } \\
\text { prevention; } \\
\text { randomized }\end{array}$ & $\begin{array}{l}65 \pm 11 \text { years (no } \\
\text { upper age limit) }\end{array}$ & $\begin{array}{l}\text { Short detection: } \\
18 \text { of } 24\end{array}$ & $\begin{array}{l}\text { Prolonged } \\
\text { detection: } 30 \text { of } \\
40\end{array}$ & $\begin{array}{l}\text { Reduction in overall } \\
\text { therapies, } \\
\text { inappropriate shocks } \\
\text { and all-cause } \\
\text { hospitalizations }\end{array}$ \\
\hline PROVIDE [138] & $\begin{array}{l}n=1670 ; \text { primary } \\
\text { prevention; } \\
\text { randomized }\end{array}$ & $\begin{array}{l}64 \pm 13 \text { years (no } \\
\text { upper age limit) }\end{array}$ & $\begin{array}{l}\text { Short detection: } \\
12 \text { beats }\end{array}$ & $\begin{array}{l}\text { Prolonged } \\
\text { detection: } \\
25 \text { beats } \\
(180-214 \mathrm{bpm}) ; \\
18 \text { beats } \\
(214-250 \mathrm{bpm}) ; \\
12 \text { beats } \\
(>250 \mathrm{bpm})\end{array}$ & $\begin{array}{l}\text { Reduction in } \\
\text { all-cause shock rate; } \\
\text { improved survival }\end{array}$ \\
\hline $\begin{array}{l}\text { PainFREE RX II } \\
\text { study [139] }\end{array}$ & $\begin{array}{l}n=634 ; \text { primary } \\
\text { or secondary } \\
\text { prevention; } \\
\text { randomized }\end{array}$ & $\begin{array}{l}67 \pm 11 \text { years (no } \\
\text { upper age limit) }\end{array}$ & $\begin{array}{l}\text { Shocks in fast VT } \\
\text { zone }\end{array}$ & $\begin{array}{l}\text { ATP in fast VT } \\
\text { zone }\end{array}$ & $\begin{array}{l}\text { Effective, safe and } \\
\text { improved quality of } \\
\text { life }\end{array}$ \\
\hline
\end{tabular}

ARP: antitachycardia pacing; bpm: beats per minute; HF: heart failure; SVTL supraventricular ventricular tachycardia; VT: ventricular tachycardia.

fraction and cardiac dyssynchrony, but it is still tempered by the lack of treatment response observed in about $30 \%$ of cases [141]. The main clinical benefits expected from CRT rely on a decrease in hospitalization (mainly of cardiovascular origin) and an increase in survival [142]. Improvements in symptoms and quality of life are also expected, and are particularly relevant in elderly patients. However, older patients usually present with more frequent 
comorbidities that might potentially interfere with these results.

\section{Selection criteria for CRT in elderly patients}

Selection criteria used to initiate CRT in the elderly are similar to those currently considered in regular indications, except for ICD combination (drug-refractory HF symptoms, LV ejection fraction $<35 \%$ and presence of ventricular dyssynchrony commonly evidenced by left bundle branch block). However, underlying cardiomyopathy is often more advanced, and may lead to a less effective CRT response. Other factors may have a negative effect, such as right bundle branch block without LV dyssynchrony, dysautonomia and hypotension, leading to suboptimal medical treatment or QRS duration $<130 \mathrm{~ms}$. The latter is supported by the results of ECHO CRT study, which reported the absence of clinical benefit together with an increased mortality rate in patients with a narrow QRS $<130 \mathrm{~ms}$, compared with the control group without CRT delivery [143].

\section{Evaluation of CRT response in the elderly}

CRT benefits include improvements in exercise tolerance and quality of life, often related to a LV reverse remodelling process [141,144-147]. Subjective criteria, such as change in NYHA functional class, are routinely applied in the elderly, who are often unable to properly perform a 6minute walk test or oxygen uptake measurement $\left(\mathrm{VO}_{2 \max }\right)$. A composite clinical endpoint can also be used, considering a "CRT responder" to be a patient who is "alive"' with an improvement in NYHA functional class and/or self-assessed symptoms, together with the absence of HF hospitalization. The non-responder will not fulfil at least one of these criteria. Echocardiography may investigate more objective criteria, such as the measurement of LV end-systolic volume and LV ejection fraction [144,146], interferences being related to abnormalities secondary to previous associated heart disease.

Regardless of the true effect of CRT, the presence of multiple comorbidities commonly seen in the elderly will further affect survival and hospitalization independently [148]. The EAARN score has been proposed (ejection fraction for $L V<22 \%$, age $>70$ years, documented episodes of $A F$, Renal dysfunction estimated by baseline glomerular filtration rate $<60 \mathrm{~mL} / \mathrm{min} / 1.73 \mathrm{~m}^{2}$, NYHA class IV), where each factor independently increases the risk of mortality in CRT patients [149].

\section{Management of CRT non-responders}

Management of an elderly patient not responding to CRT may lead one to:

- discuss if medical treatment is optimal for renal function, and/or re-evaluate the use of beta-blockers in chronic obstructive pulmonary disease;

- check appropriate functioning and delivery of the CRT system, including pacing/sensing thresholds (inappropriate atrial sensing during effort may compromise biventricular pacing), atrial and/or ventricular oversensing episodes (far field R wave, T-wave detection and noise events caused by insulation fracture, etc.), biventricular capture percentage and atrial or ventricular arrhythmias, with the aim of providing specific additional treatment, particularly AV junction ablation in case of AF; these parameters can be monitored by considering individual home monitoring systems; one should also check the absence of phrenic nerve stimulation by the LV lead, which is now anticipated by selecting a quadripolar LV lead;

- check the LV lead position on a chest X-ray, and consider repositioning if the LV lead is placed close to the apex, thus avoiding suboptimal CRT delivery [150];

- re-evaluate coronary artery disease, with angiogram to be discussed;

- perform echocardiography.

Echocardiography is performed to assess:

- LV filling time, which in theory should be $>40 \%$ of the RR interval (individual adjustment of the AV delay [and VV delay] may be proposed, but has not been well validated in controlled studies [151]);

- LV systolic function (in case of worsening of LV ejection fraction, the benefit of implanting of an additional LV lead has not been validated [152]; implantation of a second RV lead is a safe technique and may provide a greater benefit in terms of ventricular remodelling than conventional CRT, but further studies are needed to assess its long-term benefit [153]; implantation of a LV endocardial lead using a transseptal approach may promote further improvement in haemodynamics and exercise tolerance, but with higher risk of stroke, despite anticoagulation therapy - this approach is currently not recommended in the elderly because of an unfavourable benefit/risk ratio);

- RV function, which, if altered, can lead to a reduction in or discontinuation of beta-blockers.

Systematic investigation of LV dyssynchrony is not recommended, given the lack of any reproducible echocardiography variables that can translate into CRT system adjustment.

Overall, elderly patients usually experience functional improvement after CRT, similar to that observed in middleaged patients. Management of CRT non-responders remains similar, while considering a less aggressive approach in terms of reinterventions (revision of LV lead placement, addition of an RV or LV lead, LV endocardial pacing configuration). More severe cardiac and non-cardiac comorbidities are responsible for higher mortality, which can potentially interfere with the additional benefit provided by a prophylactic ICD $[148,149,154,155]$.

\section{CRT with PM or defibrillation}

Implantation of a CRT device in elderly patients may not be questionable, given the benefits in terms of quality of life, morbidity and mortality [156]. Selection of patients with a greater probability of response after CRT may be preferred (see section entitled "Evaluation of CRT response in the elderly"), as complications related to the implantation procedure have more serious consequences in the elderly. The addition of an ICD is more debatable, particularly for the primary prevention of sudden death. Available data only include subgroup analyses, so derived conclusions are strong assumptions rather than true evidence. 


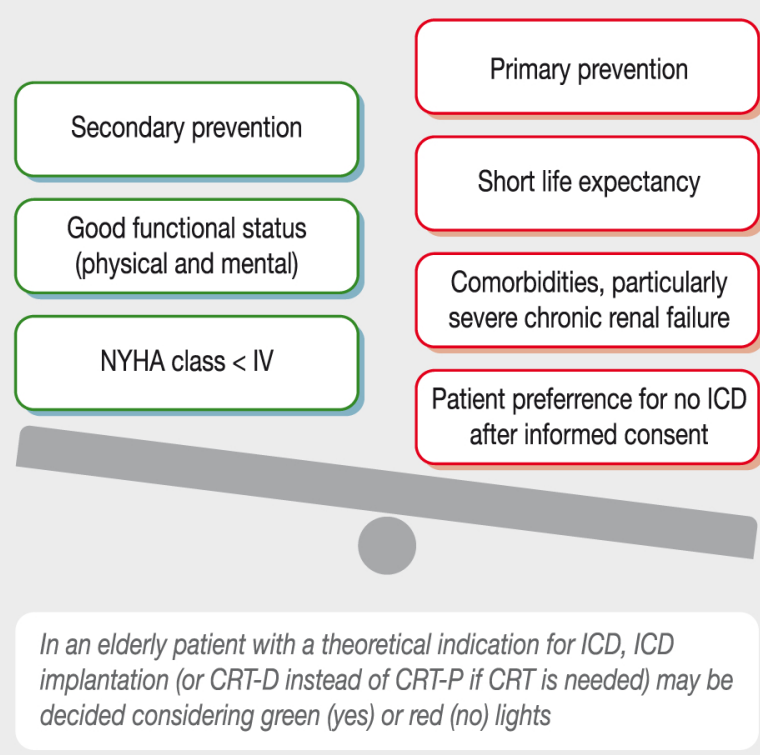

Figure 2. Possible elements for making a decision about implantable cardioverter defibrillator (ICD) implantation in an elderly patient. CRT: cardiac resynchronization therapy; CRT-D: CRT with defibrillation; CRT-P: CRT with pacemaker; NYHA: New York Heart Association.

In patients with a higher biological age (rather than chronological age), CRT with PM (CRT-P) implantation, combined with amiodarone and/or ventricular substrate-based catheter ablation in the secondary prevention of sustained VT, may be preferred to CRT with defibrillation (CRT-D), even if the level of evidence remains low $[157,158]$. Implantation of an ICD in patients aged $>80$ years is not harmless, given the risk of inappropriate therapies, especially in patients prone to developing AF. Another aspect to be discussed with the patient and/or their relatives is that the ICD, in preventing SCD, might lead to undesired death throes. Implantation of a CRT-P may be a good compromise, as it should provide large benefits and a lower risk of complications over a long period of time [159]. Indeed, the excess of mortality in CRT-P patients, as currently selected in routine clinical practice, is mainly the result of non-SCD [160]. Implantation of an ICD may only reach cost-effectiveness after 5-7years, and should only be proposed in a selected group of patients with longer life expectancy [134] (Fig. 2).

\section{Follow-up}

\section{PMs}

Follow-up recommendations in the elderly are quite similar to those for the general implanted population, which is already relatively advanced, with mean ages of $80.2,77$ and 75.5 years for single-, dual- and triple-chamber devices, respectively (2008-2009 National Health Insurance Information System database) [161]. Perioperative complications of device implantation are slightly higher in this population because of a higher rate of associated comorbidities [162], but there is no clear evidence for an increased incidence of late complications [163-165].

\section{ICDs}

Patients receiving a high-voltage device are younger in France, with mean ages of 58, 63 and 66 years for single, dual- and triple-chamber ICDs (2008-2009 National Health Insurance Information System database) [161]. Data from the USA show an older implanted population, with $30 \%$ of the patients aged between 70 and 79 years, and more than $10 \%$ aged $>80$ years [8]. Primary prevention is reported in $59 \%$ of the implanted population in France versus $75 \%$ in the USA [161]. As for low-voltage devices, the slight increase in complication rate in the elderly seems to be related to associated comorbidities and HF rather than to the device itself [114].

\section{Electromagnetic interferences}

There is no specific recommendation related to age. Check that emergency transmitters, headphones and amplifiers are not interfering with the implanted device, with dedicated medical wavelengths.

\section{Follow-up modalities and home monitoring}

Device follow-up is recommended between 3 and 12 months for PMs, and between 3 and 6 months for ICDs. More regular follow-ups are required in case of haemodynamic instability, ICD shocks, arrhythmias and when approaching the end of battery life [166].

Remote follow-up and monitoring are alternatives to traditional outpatient visits, and provide information on device function (pacing thresholds, detection, lead impedance, battery status) as well as arrhythmic and therapeutic events. Elderly patients may benefit most from this technology, as they can find clinical visits to be a disruption to their daily life and, when alone, need to call on multiple family and social resources to get to the caregiver. The ability to precisely monitor residual battery longevity reduces the need for multiple visits to the clinic. Postponing or reducing the number of device replacements is relevant in elderly patients, as replacement surgery may be associated with complications, and hospitalization may induce a deterioration in cognitive function. Remote monitoring may also be used as an alarm detection system in case of device dysfunction, arrhythmic events or lung congestion for HF.

Elderly patients have a poorer comprehension of remote monitoring than younger patients, which can lead to a lower acceptance of the system. However, education and appropriate training can improve overall comprehension and acceptance of remote monitoring [167]. Simple systems and complete automatism of the operations, requiring no direct intervention on the part of the patient, are of paramount importance [168]. When these conditions are achieved, home monitoring is expected to be valuable, even in debilitated elderly patients [169]. 


\section{Diagnostic functions: device-detected AF}

Atrial high rate episodes (AHREs) are frequently recorded in the device memories, and are well correlated with AF [170]. Physician review of stored electrograms is desirable to validate the true rate of AF. High rates of AHREs were found in PM-implanted patients with a mean age of 75 years $(89 \%$ and $54 \%$ during 24 months in patients with or without history of AF, respectively) [171]. AHREs are associated with a higher risk of ischaemic stroke [172-174]. In the ASSERT study, evaluating a device-implanted population (PMs and ICDs) of 2580 patients (mean age, 76 years) with hypertension but no history of AF, there was a higher incidence of stroke (hazard ratio 2.5) when AHREs at a rate of $>190 \mathrm{bpm}$ and lasting $>6$ minutes were recorded in the device [174].

Questions remain regarding which duration of AHREs should be considered, and whether anticoagulant therapy should be initiated in elderly patients at higher risk. In the TRENDS study, there was a doubling of stroke incidence for an $A F$ burden $>5.5$ hours during at least one of the preceding 30 days before device interrogation [172]. In an Italian registry of 725 patients (mean age, 71 years) implanted with a DDDR PM for bradycardia associated with atrial tachyarrhythmias, the risk of embolism was 3.1 times greater in case of device-detected AF episodes of $>24$ hours [175]. In the ASSERT study, only patients in the highest quartile (> 18 hours) had a significantly increased risk of thromboembolism.

To date, no intervention (i.e. anticoagulant) therapy has been validated in this population. IMPACT (Randomized Trial of Anticoagulation Guided by Remote Rhythm Monitoring in Patients with Implanted Cardioverter Defibrillator and Resynchronization Devices) evaluated the benefit of remote monitoring for atrial tachyarrhythmias, with a predefined anticoagulation plan. Compared with the conventional group, no significant difference in primary outcome (thromboembolic or haemorrhagic events) was shown in the intervention group [176]. These results should be interpreted regarding the absence of a temporal relationship between subclinical AF and stroke [177,178], AF being more frequently a marker of a population (likely to be older) at risk of stroke rather than the direct cause. Thus, despite a robust association between AHREs and stroke, there is currently a lack of consensus on the optimal management of device-detected AF.

\section{Elective replacement interval: switch from CRT-D to CRT-P}

Replacement of a CRT-D in the elderly is a common situation. The rate of CRT device implantation is increasing, and the percentage of ICDs among those devices is also increasing. In France in 2008, the mean age at CRT-D implantation was 66 years [161]. Patient survival is likely to exceed that of the devices [179], and 50\% of CRT-D devices may have to be replaced at 4 years because of battery depletion [180].

At CRT-D replacement time because of battery depletion, several factors may favour its replacement with a CRT-P in elderly patients:
- in case of LV ejection fraction improvement and in the absence of appropriate therapies, the risk of SCD is probably low; around $25 \%$ of the patients, initially implanted for a primary prevention indication, may no longer meet the guideline-driven indication for an ICD at the time of generator replacement [181]; if appropriate therapies have been delivered, for legal considerations, it seems preferable to replace the ICD, unless this contradicts wishes expressed earlier when the patient was in good condition;

- the occurrence of appropriate therapies is lower in older patients [182];

- older people obviously have a higher annual rate of death - mortality rates 1 and 2 years after ICD replacement in octogenarians were $23 \%$ and $38 \%$, respectively, in a recent study [120]; an increase in mortality of $8 \%$ by year of age after 75 years was found in ICD patients implanted for primary prevention [115]; finally, SCD accounts for 51\% of deaths before 50 years and only $26 \%$ of deaths over 80 years [108].

Evaluation of the patient's clinical status is therefore crucial. The prevalence of comorbidities is significantly higher at ICD replacement time than at the time of primo implantation; this was the case in a recent analysis of chronic kidney disease ( $29 \%$ vs. $22 \%)$, AF ( $24 \%$ vs. $16 \%$ ) and neoplastic disease $(14 \%$ vs. $3 \%)$ [181].

Ethical, moral and legal aspects have then to be considered [183]. The patient or their legal representative has the right to refuse or to claim the ICD replacement. If the patient can understand the nature and the consequences of their decisions, they are then legally competent to take these decisions. From an ethical and legal point of view, there is no difference between refusing an ICD implantation and refusing an ICD replacement, and not replacing an ICD does not correspond to assisted suicide or euthanasia (see section entitled "Deactivating a patient's ICD at the end of life'). The patient's informed consent is needed, and one should clearly inform them about the role of the ICD, and the potential consequences of its replacement with a CRTP. Some patients would prefer to have the "opportunity" of dying suddenly; for others the idea of no longer being protected from SCD would be unbearable.

Finally, technical aspects should be considered. It is no longer possible to simply replace a CRT-D by a CRT-P with the DF4 ICD leads. Adding a RV pacing lead would not seem reasonable, and connectors are not yet available. In older patients, we should therefore consider the use of a DF1 lead at the time of primo implantation. Thus, when a CRT-D reaches the elective replacement interval time in elderly patients, one should consider replacing it with a CRT-P, taking into account the patient's clinical status and preferences.

\section{Deactivating a patient's ICD at the end of life}

The status of the ICD patient may deteriorate because of the progression of cardiomyopathy or worsening of a comorbidity. When a patient reaches the end of life, the question of deactivating the ICD can be legitimate, and the factors in this discussion are not age related [184]. 
It has been estimated that $20 \%$ of patients with an ICD receive shocks during their last few weeks of life, whether or not they are appropriate; their use seems questionable. Stopping an ICD at the end of life in a patient can be achieved in different ways, which are ethically and legally equivalent: implanting a magnet, programming a device or not replacing a worn-out device. While an ICD is also used for its antibradycardia function in an individual who might be PM-dependent, this should be distinguished from its antitachycardia function, as inhibiting it would have immediate consequences for quality of life and survival.

Legally, stopping the antitachycardia functions of an ICD is akin to stopping any given treatment. This delicate matter should ideally be discussed at the time of primo implantation, and should be part of the consent form signed by the patient. Many patients ignore the actual function of ICDs [185]. Likewise, it would be preferable for the patient to state their opinion, to assist decision-making when their state of consciousness makes them less capable of doing so. A patient has the right to request the suspension of a therapy at all times. The physician is obliged to respect the patient's will, after informing them of the consequences of the choice [186]. The trusted person cannot consent in place of the patient, but can give an advisory opinion according to the patient's expressed wishes. While the patient is under guardianship, the guardian should give their consent.

However, it is also the physician's responsibility and duty to discuss the matter with the patient or trusted person when the situation arises, even and especially when the patient or the patient's family does not ask to discuss it. Indeed, in French legislation, the physician should "under all circumstances strive to relieve disease-related suffering and abstain from any intensive medication", the latter being defined as "unreasonable obstinacy owing to a stubborn refusal to recognise that a person is bound to die and cannot be cured" (Article R. 4127-37 of the French Public Health Code). The physician can decide to "limit or suspend an unnecessary or disproportionate treatment whose sole aim is to sustain life by artificial means" (Article L. 111113 of the French Public Health Code). "The physician shall safeguard the dignity of the dying person and ensure the quality of the person's end of life"' (Article L.1110-10 of the French Public Health Code).

Deactivating or not replacing an ICD is, in all cases, subject to obtaining clear consent. Under no circumstances can it be considered assisted suicide or euthanasia [186]. Death is not directly caused by a prescription or a medical act; it is the result of the underlying disease. A physician is not obliged to personally make the decision to deactivate an $I C D$, if this decision is not in accord with their moral or religious principles. In this case, it should simply be proposed that another practitioner make the decision instead. Likewise, the patient, having given consent, can reconsider the decision at any time.

Accompanying the patient and the patient's family in end-of-life decisions is done jointly with the healthcare team, who might need to call upon a palliative care team to treat uncomfortable symptoms. Matters of a spiritual nature can also be discussed.

Deactivating an ICD in a patient at the end of life is authorized by the law, subject to following a collaborative procedure, and obtaining the consent of the patient or the patient's legal representative. This procedure can also be requested by the patient, but it should, above all, be proposed by the practitioner out of respect for the patient's dignity, and to avoid any ethically and legally reprehensible intensive medication.

\section{Novel cardiac devices for older patients, and perspectives}

\section{Leadless PMs}

Leadless PMs, first implanted in humans in 2013, are likely to replace standard VVIR cardiac pacing, particularly in older patients; they will prevent some complications related to:

- the pulse generator, including haematomas, extrusions and pocket infections, facilitated by device replacements, long-term anticoagulation and cutaneous fragility;

- the venous access as well as the lead implantation, including pneumothorax, tamponade and dislodgement.

Over the long-term, the cardiac pacing lead is generally considered the system's weakest link, associated with venous thromboses, breakdown of the insulation or wire rupture and infections. The rate of these complications is increased by concomitant disorders, which are themselves promoted by older age.

The first commercially available leadless PM (Nanostim ${ }^{\circledR}$; St. Jude Medical, St. Paul, MN, USA) is a VVIR device, which weighs $2 \mathrm{~g}$ and is implanted at the RV apex via a large $18 \mathrm{~F}$ femoral introducer. The second $0.8 \mathrm{cc} / 2 \mathrm{~g}$ device (Micra ${ }^{\circledR}$; Medtronic Inc., Minneapolis, MN, USA) is implanted via a $22 \mathrm{~F}$ femoral introducer. The absence of lead decreases the rate of lead-related complications. The risk of infection is decreased, the connections are eliminated and the system is MRI-compatible. The absence of scar and pectoral implant eliminates central and subclavian venous thrombosis, cutaneous extrusion and haematomas.

The systems are currently limited to VVIR pacing. Implant feasibility was confirmed in 2014, in patients aged $77 \pm 8$ years [187]. However, it is noteworthy that a patient experienced a fatal perforation of the right ventricle with tamponade and cerebral vascular accident, highlighting the importance of being careful with these elderly and fragile patients. In a multicentre study, the leadless Nanostim ${ }^{\circledR}$ device met prespecified pacing and sensing requirements in the large majority of patients, although device-related serious adverse events occurred in approximately 1 in 15 patients [188]. In an analysis with a historical comparison study, the Micra ${ }^{\circledR}$ device had a safety profile similar to that of a transvenous system, while providing low and stable pacing thresholds [189].

The long-term status of these devices is unknown, particularly the risk of endothelialization and fibrosis, which might hamper their extraction. While it will mandate the abandonment of the leadless electrode and a reimplantation or extraction, this complication is considerably less consequential for older patients. Currently, up to $25 \%$ of patients are paced in VVIR mode, which is particularly suitable in the elderly, who are likely to undergo few device replacements.

On-going research is focusing on energy harvester rechargeable systems or biopiles [190], with a view to 
further decreasing the size of the devices, while increasing their longevity and enabling communications among various leadless systems implanted in the right atrium, right ventricle and left heart. Elderly patients are likely to benefit from the innovations, which are expected to decrease the rate of complications at the time of implantation or during the longer-term follow-up.

\section{Subcutaneous ICDs}

The subcutaneous ICD is emerging as a therapy for the prevention of SCD, avoiding the complications associated with transvenous leads [191]. The subcutaneous ICD is essentially promising in terms of reduction of electrode-related complications, such as infection or lead failure, which may be more relevant for relatively young and active patients [192]. This may, however, be an option in elderly patients in case of limited vascular access or persistent infection.

\section{Conclusions}

Cardiac pacing, CRT and ICD therapy may remain effective despite advanced age in selected patients, when they have minimum comorbidities, particularly for septuagenarians and octogenarians. In the oldest patients, discussion regarding the effect of implantable devices on the mode of death (ICD preventing SCD but exposing the recipient to the risk of prolonged and progressive HF) takes a particular place in decision-making according to patient choice [120,134]. Physiological age and comorbidities should be the decisive factor in making a decision about device implantation selection for survival and well-being benefit in elderly patients. These patients may, in the future, be good candidates for leadless pacing. Management of CRT issues remains globally the same, while considering a less aggressive approach at implantation or for reinterventions. Beyond the clinical sense, ICD intervention among the elderly as a group may be less cost-effective, but cost-effectiveness is expected when ICDs are implanted in patients expected to live for a sufficient time (e.g. > 5-7years) after implantation.

\section{Disclosure of interest}

L.F. Consulting and/or lecture fees from the companies Boston Scientific and Medtronic.

C.A. Consulting and/or lecture fees from the companies LivaNova and Medtronic.

F.A. Consulting and/or lecture fees from the companies LivaNova, Medtronic, St. Jude Medical.

S.B. Consulting and/or lecture fees from the companies Medtronic, Boston Scientific and Sorin Group/LivaNova.

N.C. Consulting and/or lecture fees from the company Medtronic.

P.D. Consulting and/or lecture fees from the companies Medtronic, Boston Scientific, St. Jude Medical and Sorin Group/LivaNova.

J.-C. D. Consulting and/or lecture fees from the companies Biotronik, Boston Scientific, Medtronic, Sorin Group and St. Jude Medical.

P.F. Consulting and/or lecture fees from the companies sanofi-aventis, Bayer, Merck Serono, Novartis and Servier.
D.G. Consulting and/or lecture fees from the companies Medtronic, Boston Scientific, St. Jude Medical and Biotronik.

O.H. Consulting and/or lecture fees from the companies Boehringer Ingelheim, sanofi-aventis, Daichi Sankyo, Bayer Schering Pharma, Bristol-Myers Squibb, Servier, Abbott and Novartis.

D.K. Consulting and/or lecture fees from the companies St. Jude Medical, Medtronic, Sorin Group, Boston Scientific and Biotronik.

J.M. Consulting and/or lecture fees from the companies Biotronik, Boston Scientific, LivaNova, Medtronic, St. Jude Medical, Bayer, Boehringer, Bristol-Myers Squibb, Daichi Sankyo, Pfizer, Amgen, MSD, Novartis and Sanofi.

J.-L.P. Consulting and/or lecture fees from the companies St. Jude Medical and Boston Scientific.

N.S. Consulting and/or lecture fees from the companies Biotronik, Boston Scientific, Medtronic, Sorin Group and St. Jude Medical.

O.P. Consulting and/or lecture fees from the companies Medtronic, St. Jude Medical and Boston Scientific.

The other authors declare that they have no competing interest.

\section{Appendix 1. Katz Index of Independence in Activities of Daily Living (Katz ADL) [75]}

Bathing (sink, bath or shower, body care)

$1 \square \quad$ no need for any assistance

$1 / 2 \quad \square \quad$ need for partial assistance

$0 \quad \square \quad$ dependence

Dressing (gets clothes from closets and drawers, including undergarments and outer garments; uses buttons and zips)

$1 \square \quad$ no need for any assistance

$1 / 2 \square$ autonomy in choosing clothes and dressing, need for assistance in tying shoes

$0 \quad \square \quad$ dependence

Toileting (to urinate or defecate, wipe and put clothes back on)

$1 \square \quad$ no need for any assistance

$1 / 2 \quad \square \quad$ must be accompanied or needs assistance to undress or put clothes back on

$0 \quad \square \quad$ cannot go to the toilet alone or does not use a bedpan

Transferring

$1 \quad \square \quad$ no need for any assistance to get in and out of bed, sit down or get up from a chair (can use an assistive device such as a cane or walker)

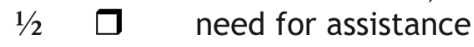
$0 \quad \square \quad$ does not get out of bed (bedridden)

\section{Continence}
$1 \square$ complete control of urine and stools
$1 / 2 \quad \square \quad$ occasional accidents
$0 \quad \square \quad$ complete incontinence

Feeding

$1 \quad \square \quad$ no need for any assistance

$1 / 2 \quad \square \quad$ need for assistance to cut meat, butter bread or peel fruit

$0 \quad \square \quad$ need for total assistance

\section{Score out of 6}

$($ normal score $=6 / 6)$ 


\section{Appendix 2. Mini Geriatric Depression Scale; assessment of mood}

Ask the questions to the patient, specifying that the responses should refer to the very recent past, ideally the last week, and not years ago or right now.

1. Do you often feel discouraged and sad? yes $=1$, no $=0$

2. Do you feel that your life is empty? yes $=1$, no $=0$

3. Are you happy most of the time? yes $=0$, no $=1$

4. Do you feel that your situation is hopeless? yes $=1$, no $=0$

\section{Scoring}

If the total score is $\geq 1$, strong likelihood of depression.

If the total score $=0$, strong likelihood of absence of depression.

\section{References}

[1] Bardy GH, Lee KL, Mark DB, et al. Amiodarone or an implantable cardioverter defibrillator for congestive heart failure. N Engl J Med 2005;352:225-37.

[2] Buxton AE, Lee KL, Fisher JD, Josephson ME, Prystowsky EN, Hafley G. A randomized study of the prevention of sudden death in patients with coronary artery disease. Multicenter Unsustained Tachycardia Trial Investigators. N Engl J Med 1999;341:1882-90.

[3] Connolly SJ, Gent M, Roberts RS, et al. Canadian implantable defibrillator study (CIDS): a randomized trial of the implantable cardioverter defibrillator against amiodarone. Circulation 2000;101:1297-302.

[4] Kuck KH, Cappato R, Siebels J, Ruppel R. Randomized comparison of antiarrhythmic drug therapy with implantable defibrillators in patients resuscitated from cardiac arrest: the Cardiac Arrest Study Hamburg (CASH). Circulation 2000; $102: 748-54$.

[5] Moss AJ, Hall WJ, Cannom DS, et al. Improved survival with an implanted defibrillator in patients with coronary disease at high risk for ventricular arrhythmia. Multicenter Automatic Defibrillator Implantation Trial Investigators. N Engl J Med 1996;335:1933-40.

[6] Moss AJ, Zareba W, Hall WJ, et al. Prophylactic implantation of a defibrillator in patients with myocardial infarction and reduced ejection fraction. N Engl J Med 2002;346: $877-83$

[7] The Antiarrhythmics versus Implantable Defibrillators (AVID) Investigators. A comparison of antiarrhythmic drug therapy with implantable defibrillators in patients resuscitated from near-fatal ventricular arrhythmias. N Engl J Med 1997;337:1576-83.

[8] Epstein AE, Kay GN, Plumb VJ, et al. Implantable cardioverter defibrillator prescription in the elderly. Heart Rhythm 2009;6:1136-43.

[9] Proclemer A, Zecchin M, D'Onofrio A, et al. [The pacemaker and implantable cardioverter defibrillator registry of the Italian Association Arrhythmology Cardiac Pacing and cardiac pacing - annual report 2013]. G Ital Cardiol (Rome) 2014;15:638-50.

[10] Ruskin JN, Camm AJ, Zipes DP, Hallstrom AP, McGrory-Usset ME. Implantable cardioverter defibrillator utilization based on discharge diagnoses from Medicare and managed care patients. J Cardiovasc Electrophysiol 2002;13:38-43.
[11] Anderson GF, Hussey PS. Population aging: a comparison among industrialized countries. Health Aff Proj Hope 2000;19:191-203.

[12] Wiener JM, Tilly J. Population ageing in the United States of America: implications for public programmes. Int J Epidemiol 2002;31:776-81.

[13] Chan PS, Nallamothu BK, Spertus JA, et al. Impact of age and medical comorbidity on the effectiveness of implantable cardioverter defibrillators for primary prevention. Circ Cardiovasc Qual Outcomes 2009;2:16-24.

[14] Earley A, Persson R, Garlitski AC, Balk EM, Uhlig K. Effectiveness of implantable cardioverter defibrillators for primary prevention of sudden cardiac death in subgroups a systematic review. Ann Intern Med 2014;160:111-21.

[15] Healey JS, Hallstrom AP, Kuck KH, et al. Role of the implantable defibrillator among elderly patients with a history of life-threatening ventricular arrhythmias. Eur Heart J 2007;28:1746-9.

[16] Huang DT, Sesselberg HW, McNitt S, et al. Improved survival associated with prophylactic implantable defibrillators in elderly patients with prior myocardial infarction and depressed ventricular function: a MADIT-II substudy. J Cardiovasc Electrophysiol 2007;18:833-8.

[17] Kong MH, Al-Khatib SM, Sanders GD, Hasselblad V, Peterson ED. Use of implantable cardioverter defibrillators for primary prevention in older patients: a systematic literature review and meta-analysis. Cardiol J 2011;18:503-14.

[18] Russo AM, Stainback RF, Bailey SR, et al. ACCF/HRS/AHA/ASE/HFSA/SCAI/SCCT/SCMR 2013 appropriate use criteria for implantable cardioverter defibrillators and cardiac resynchronization therapy: a report of the American College of Cardiology Foundation appropriate use criteria task force, Heart Rhythm Society, American Heart Association, American Society of Echocardiography, Heart Failure Society of America, Society for Cardiovascular Angiography and Interventions. Society of Cardiovascular Computed Tomography, and Society for Cardiovascular Magnetic Resonance. J Am Coll Cardiol 2013;61: 1318-68.

[19] Santangeli P, Di Biase L, Dello Russo A, et al. Metaanalysis: age and effectiveness of prophylactic implantable cardioverter defibrillators. Ann Intern Med 2010;153:592-9.

[20] Chow GV, Marine JE, Fleg JL. Epidemiology of arrhythmias and conduction disorders in older adults. Clin Geriatr Med 2012;28:539-53.

[21] Mirza M, Strunets A, Shen WK, Jahangir A. Mechanisms of arrhythmias and conduction disorders in older adults. Clin Geriatr Med 2012;28:555-73.

[22] Mymin D, Mathewson FA, Tate RB, Manfreda J. The natural history of primary first-degree atrioventricular heart block. N Engl J Med 1986;315:1183-7.

[23] Cheng S, Keyes MJ, Larson MG, et al. Long-term outcomes in individuals with prolonged PR interval or first-degree atrioventricular block. JAMA 2009;301:2571-7.

[24] Rossi S, Fortunati I, Carnevali L, et al. The effect of aging on the specialized conducting system: a telemetry ECG study in rats over a 6-month period. PLoS One 2014;9:e112697.

[25] Kreger BE, Anderson KM, Kannel WB. Prevalence of intraventricular block in the general population: the Framingham Study. Am Heart J 1989;117:903-10.

[26] Fahy GJ, Pinski SL, Miller DP, et al. Natural history of isolated bundle branch block. Am J Cardiol 1996;77:1185-90.

[27] Kojic EM, Hardarson T, Sigfusson N, Sigvaldason H. The prevalence and prognosis of third-degree atrioventricular conduction block: the Reykjavik study. J Intern Med 1999;246:81-6.

[28] Camm AJ, Evans KE, Ward DE, Martin A. The rhythm of the heart in active elderly subjects. Am Heart J 1980;99:598-603. 
[29] Grolleau R, Pasquié JL, Leclercq F. Arythmies du sujet âgé. In: Bounhoure JP, editor. Les effets du vieillissement sur le système cardiovasculaire. Paris: Frison Roche; 1999. p. $141-60$.

[30] Raybaud F, Camous JP, Tibi T, Baudouy M, Morand P. [Severe arrhythmia in the elderly: a prospective hospital study]. Arch Mal Coeur Vaiss 1995;88:27-33.

[31] Sherman H, Sandberg S, Fineberg HV. Exponential increase in age-specific prevalence of ventricular dysrhythmia among males. J Chronic Dis 1982;35:743-50.

[32] Manolio TA, Furberg CD, Rautaharju PM, et al. Cardiac arrhythmias on 24-h ambulatory electrocardiography in older women and men: the Cardiovascular Health Study. J Am Coll Cardiol 1994;23:916-25.

[33] Delacretaz E, Stevenson WG, Ellison KE, Maisel WH, Friedman PL. Mapping and radiofrequency catheter ablation of the three types of sustained monomorphic ventricular tachycardia in non-ischemic heart disease. J Cardiovasc Electrophysiol 2000;11:11-7.

[34] Lopera G, Stevenson WG, Soejima K, et al. Identification and ablation of three types of ventricular tachycardia involving the his-purkinje system in patients with heart disease. J Cardiovasc Electrophysiol 2004;15:52-8.

[35] Pasquie JL, Macia JC, Leclercq F, Grolleau R. [Ventricular tachycardia due to branch to branch re-entry]. Arch Mal Coeur Vaiss 2005;98(Spec No. 5):15-20.

[36] Rubart M, Zipes DP. Mechanisms of sudden cardiac death. J Clin Invest 2005;115:2305-15.

[37] Murphy DJ, Murray AM, Robinson BE, Campion EW. Outcomes of cardiopulmonary resuscitation in the elderly. Ann Intern Med 1989;111:199-205.

[38] Tresch D, Heudebert G, Kutty K, Ohlert J, VanBeek K, Masi A. Cardiopulmonary resuscitation in elderly patients hospitalized in the 1990s: a favorable outcome. J Am Geriatr Soc 1994;42:137-41.

[39] Tresch DD, Thakur R, Hoffmann RG, Brooks HL. Comparison of outcome of resuscitation of out-of-hospital cardiac arrest in persons younger and older than 70 years of age. Am J Cardiol 1988;61:1120-2.

[40] Tresch DD, Thakur RK, Hoffmann RG, Aufderheide TP, Brooks HL. Comparison of outcome of paramedic-witnessed cardiac arrest in patients younger and older than 70 years. Am J Cardiol 1990;65:453-7.

[41] Bayer AJ, Ang BC, Pathy MS. Cardiac arrests in a geriatric unit. Age Ageing 1985;14:271-6.

[42] Lloyd-Jones D, Adams R, Carnethon M, et al. Heart disease and stroke statistics - 2009 update: a report from the American Heart Association Statistics Committee and Stroke Statistics Subcommittee. Circulation 2009;119:e21-181.

[43] McMurray JJ, Adamopoulos S, Anker SD, et al. ESC Guidelines for the diagnosis and treatment of acute and chronic heart failure 2012: the task force for the diagnosis and treatment of acute and chronic heart failure 2012 of the European Society of Cardiology. Developed in collaboration with the Heart Failure Association (HFA) of the ESC. Eur Heart $\mathrm{J}$ 2012;33:1787-847.

[44] Lloyd-Jones D, Adams RJ, Brown TM, et al. Executive summary: heart disease and stroke statistics - 2010 update: a report from the American Heart Association. Circulation 2010;121:948-54.

[45] Roger VL, Go AS, Lloyd-Jones DM, et al. Heart disease and stroke statistics - 2011 update: a report from the American Heart Association. Circulation 2011;123:e209-18.

[46] Braunstein JB, Anderson GF, Gerstenblith G, et al. Noncardiac comorbidity increases preventable hospitalizations and mortality among Medicare beneficiaries with chronic heart failure. J Am Coll Cardiol 2003;42:1226-33.
[47] From AM, Leibson CL, Bursi F, et al. Diabetes in heart failure: prevalence and impact on outcome in the population. Am J Med 2006;119:591-9.

[48] Stein GY, Kremer A, Shochat T, et al. The diversity of heart failure in a hospitalized population: the role of age. J Card Fail 2012;18:645-53.

[49] Bhatia RS, Tu JV, Lee DS, et al. Outcome of heart failure with preserved ejection fraction in a population-based study. $\mathrm{N}$ Engl J Med 2006;355:260-9.

[50] Azad N, Kathiravelu A, Minoosepeher S, Hebert P, Fergusson D. Gender differences in the etiology of heart failure: a systematic review. J Geriatr Cardiol 2011;8:15-23.

[51] Jensen PN, Gronroos NN, Chen LY, et al. Incidence of and risk factors for sick sinus syndrome in the general population. J Am Coll Cardiol 2014;64:531-8.

[52] Lewis EF, Hellkamp AS, Pfeffer MA, et al. The association of the heart failure score with mortality and heart failure hospitalizations in elderly patients: insights from the Mode Selection Trial (MOST). Am Heart J 2006;151:699-705.

[53] Chien CC, Yen CS, Wang JJ, et al. Reverse epidemiology of hypertension-mortality associations in hemodialysis patients: a long-term population-based study. Am J Hypertens 2012;25:900-6.

[54] Guder G, Frantz S, Bauersachs J, et al. Reverse epidemiology in systolic and nonsystolic heart failure: cumulative prognostic benefit of classical cardiovascular risk factors. Circ Heart Fail 2009;2:563-71.

[55] Kies P, Bax JJ, Molhoek SG, et al. Comparison of effectiveness of cardiac resynchronization therapy in patients with versus without diabetes mellitus. Am J Cardiol 2005;96: $108-11$.

[56] Antonio N, Lourenco C, Teixeira R, et al. Cardiac resynchronization therapy is effective even in elderly patients with comorbidities. J Interv Card Electrophysiol 2010;27:61-8.

[57] Fantoni C, Regoli F, Ghanem A, et al. Long-term outcome in diabetic heart failure patients treated with cardiac resynchronization therapy. Eur J Heart Fail 2008;10:298-307.

[58] Martin DT, McNitt S, Nesto RW, Rutter MK, Moss AJ. Cardiac resynchronization therapy reduces the risk of cardiac events in patients with diabetes enrolled in the multicenter automatic defibrillator implantation trial with cardiac resynchronization therapy (MADIT-CRT). Circ Heart Fail 2011;4:332-8.

[59] Wittenberg SM, Cook JR, Hall WJ, et al. Comparison of efficacy of implanted cardioverter defibrillator in patients with versus without diabetes mellitus. Am J Cardiol 2005;96:417-9.

[60] Maisel WH, Stevenson LW. Atrial fibrillation in heart failure: epidemiology, pathophysiology, and rationale for therapy. Am J Cardiol 2003;91:2D-8D.

[61] Upadhyay GA, Choudhry NK, Auricchio A, Ruskin J, Singh JP. Cardiac resynchronization in patients with atrial fibrillation: a meta-analysis of prospective cohort studies. J Am Coll Cardiol 2008;52:1239-46.

[62] van Boven N, Theuns D, Bogaard K, et al. Atrial fibrillation in cardiac resynchronization therapy with a defibrillator: a risk factor for mortality, appropriate and inappropriate shocks. J Cardiovasc Electrophysiol 2013;24:1116-22.

[63] Borleffs CJ, van Rees JB, van Welsenes GH, et al. Prognostic importance of atrial fibrillation in implantable cardioverter defibrillator patients. J Am Coll Cardiol 2010;55:879-85.

[64] Ezekowitz J, McAlister FA, Humphries KH, et al. The association among renal insufficiency, pharmacotherapy, and outcomes in 6427 patients with heart failure and coronary artery disease. J Am Coll Cardiol 2004;44:1587-92.

[65] Goldenberg I, Vyas AK, Hall WJ, et al. Risk stratification for primary implantation of a cardioverter defibrillator in 
patients with ischemic left ventricular dysfunction. J Am Coll Cardiol 2008;51:288-96.

[66] Boerrigter G, Costello-Boerrigter LC, Abraham WT, et al. Cardiac resynchronization therapy improves renal function in human heart failure with reduced glomerular filtration rate. J Card Fail 2008;14:539-46.

[67] Fung JW, Szeto CC, Chan JY, et al. Prognostic value of renal function in patients with cardiac resynchronization therapy. Int J Cardiol 2007;122:10-6.

[68] Tsai V, Goldstein MK, Hsia HH, et al. Influence of age on perioperative complications among patients undergoing implantable cardioverter defibrillators for primary prevention in the United States. Circ Cardiovasc Qual Outcomes 2011;4:549-56.

[69] Koplan BA, Epstein LM, Albert CM, Stevenson WG. Survival in octogenarians receiving implantable defibrillators. Am Heart J 2006;152:714-9.

[70] Lee DS, Tu JV, Austin PC, et al. Effect of cardiac and noncardiac conditions on survival after defibrillator implantation. J Am Coll Cardiol 2007;49:2408-15.

[71] Ellis G, Whitehead MA, O'Neill D, Langhorne P, Robinson D. Comprehensive geriatric assessment for older adults admitted to hospital. Cochrane Database Syst Rev 2011:CD006211.

[72] Kenis C, Decoster L, Van Puyvelde K, et al. Performance of two geriatric screening tools in older patients with cancer. J Clin Oncol 2014;32:19-26.

[73] Haute Autorité de santé. Comment réduire les réhospitalisations évitables des personnes âgées?; 2015. Available at: http://www.has-sante.fr/portail/jcms/c_1602735/fr/ comment-reduire-les-rehospitalisations-evitables-despersonnes-agees [accessed date: 28th July 2015].

[74] Haute Autorité de santé. Comment repérer la fragilité en soins ambulatoires ?; 2015. Available at: http://www. has-sante. fr/portail/jcms/c_1602970/fr/comment-repererla-fragilite-en-soins-ambulatoires [accessed date: 28th July 2015].

[75] Katz S, Ford AB, Moskowitz RW, Jackson BA, Jaffe MW. Studies of illness in the aged. The Index of ADL: a standardized measure of biological and psychosocial function. JAMA 1963;185:914-9.

[76] Meldon SW, Mion LC, Palmer RM, et al. A brief riskstratification tool to predict repeat emergency department visits and hospitalizations in older patients discharged from the emergency department. Acad Emerg Med 2003; 10:224-32.

[77] Haute Autorité de santé. Comment prendre en charge les personnes âgées fragiles en ambulatoire ?; 2015. Available at: http://www.has-sante.fr/portail/jcms/c_1718248/fr/ comment-prendre-en-charge-les-personnes-agees-fragilesen-ambulatoire [accessed date: 28th July 2015].

[78] Folstein MF, Folstein SE, McHugh PR. Mini-mental state. A practical method for grading the cognitive state of patients for the clinician. J Psychiatr Res 1975;12:189-98.

[79] de Rotrou J, Battal-Merlet L, Wenisch E, et al. Relevance of 10 -min delayed recall in dementia screening. Eur $\mathrm{J}$ Neurol 2007; 14:144-9.

[80] Nemeroff CB. The curiously strong relationship between cardiovascular disease and depression in the elderly. Am J Geriatr Psychiatry 2008;16:857-60.

[81] Dominguez-Rodriguez A, Abreu-Gonzalez P, Jimenez-Sosa $A$, et al. The impact of frailty in older patients with non-ischaemic cardiomyopathy after implantation of cardiac resynchronization therapy defibrillator. Europace 2015;17:598-602.

[82] Morley JE, Vellas B, van Kan GA, et al. Frailty consensus: a call to action. J Am Med Dir Assoc 2013;14:392-7.

[83] Vellas B, Balardy L, Gillette-Guyonnet S, et al. Looking for frailty in community-dwelling older persons: the
Gerontopole Frailty Screening Tool (GFST). J Nutr Health Aging 2013;17:629-31.

[84] Brignole M, Auricchio A, Baron-Esquivias G, et al. 2013 ESC guidelines on cardiac pacing and cardiac resynchronization therapy: the task force on cardiac pacing and resynchronization therapy of the European Society of Cardiology (ESC). Developed in collaboration with the European Heart Rhythm Association (EHRA). Europace 2013;15: 1070-118.

[85] Andersen HR, Nielsen JC, Thomsen PE, et al. Long-term follow-up of patients from a randomised trial of atrial versus ventricular pacing for sick-sinus syndrome. Lancet 1997;350:1210-6.

[86] Lamas GA, Orav EJ, Stambler BS, et al. Quality of life and clinical outcomes in elderly patients treated with ventricular pacing as compared with dual-chamber pacing. Pacemaker Selection in the Elderly Investigators. N Engl J Med 1998;338:1097-104.

[87] Lamas GA, Lee KL, Sweeney MO, et al. Ventricular pacing or dual-chamber pacing for sinus-node dysfunction. N Engl J Med 2002;346:1854-62.

[88] Link MS, Hellkamp AS, Estes 3rd NA, et al. High incidence of pacemaker syndrome in patients with sinus node dysfunction treated with ventricular-based pacing in the Mode Selection Trial (MOST). J Am Coll Cardiol 2004;43:2066-71.

[89] Kerr CR, Connolly SJ, Abdollah H, et al. Canadian trial of physiological pacing: effects of physiological pacing during long-term follow-up. Circulation 2004;109:357-62.

[90] Lin JC, Goldstein M, Benditt DG. UKPACE: to die, or not to die. Is that the question? Europace 2006;8:852-4.

[91] Toff WD, Camm AJ, Skehan JD, United Kingdom P. Cardiovascular Events Trial I. Single-chamber versus dual-chamber pacing for high-grade atrioventricular block. N Engl J Med 2005;353:145-55.

[92] Chao TF, Liu CJ, Tuan TC, et al. Long-term prognosis of patients older than ninety years after permanent pacemaker implantation: does the procedure save the patients? Can J Cardiol 2014;30:1196-201.

[93] Antonelli D, Freedberg NA, Bushari LI, Feldman A, Turgeman Y. Permanent pacing in nonagenarians over 20-year period. Pacing Clin Electrophysiol 2015;38:48-53.

[94] Stockburger M, Boveda S, Moreno J, et al. Long-term clinical effects of ventricular pacing reduction with a changeover mode to minimize ventricular pacing in a general pacemaker population. Eur Heart J 2015;36:151-7.

[95] Sweeney MO, Bank AJ, Nsah E, et al. Minimizing ventricular pacing to reduce atrial fibrillation in sinus-node disease. $\mathrm{N}$ Engl J Med 2007;357:1000-8.

[96] Sweeney MO, Hellkamp AS, Ellenbogen KA, et al. Adverse effect of ventricular pacing on heart failure and atrial fibrillation among patients with normal baseline QRS duration in a clinical trial of pacemaker therapy for sinus node dysfunction. Circulation 2003;107:2932-7.

[97] de Cock CC, Giudici MC, Twisk JW. Comparison of the haemodynamic effects of right ventricular outflow-tract pacing with right ventricular apex pacing: a quantitative review. Europace 2003;5:275-8.

[98] Stambler BS, Ellenbogen K, Zhang X, et al. Right ventricular outflow versus apical pacing in pacemaker patients with congestive heart failure and atrial fibrillation. J Cardiovasc Electrophysiol 2003;14:1180-6.

[99] Barba-Pichardo R, Morina-Vazquez P, Fernandez-Gomez JM, Venegas-Gamero J, Herrera-Carranza M. Permanent Hisbundle pacing: seeking physiological ventricular pacing. Europace 2010;12:527-33.

[100] Lamas GA, Knight JD, Sweeney MO, et al. Impact of rate-modulated pacing on quality of life and exercise capacity - evidence from the Advanced Elements of 
Pacing Randomized Controlled Trial (ADEPT). Heart Rhythm 2007;4:1125-32.

[101] Lau CP, Rushby J, Leigh-Jones M, et al. Symptomatology and quality of life in patients with rate-responsive pacemakers: a double-blind, randomized, crossover study. Clin Cardiol 1989;12:505-12.

[102] Oto MA, Muderrisoglu H, Ozin MB, et al. Quality of life in patients with rate responsive pacemakers: a randomized, crossover study. Pacing Clin Electrophysiol 1991;14:800-6.

[103] Padeletti L, Pieragnoli P, Di Biase L, et al. Is a dual-sensor pacemaker appropriate in patients with sino-atrial disease? Results from the DUSISLOG study. Pacing Clin Electrophysiol 2006;29:34-40.

[104] Sulke N, Chambers J, Dritsas A, Sowton E. A randomized double-blind crossover comparison of four rate-responsive pacing modes. J Am Coll Cardiol 1991;17:696-706.

[105] Levine GN, Gomes AS, Arai AE, et al. Safety of magnetic resonance imaging in patients with cardiovascular devices: an American Heart Association scientific statement from the Committee on Diagnostic and Interventional Cardiac Catheterization. Council on Clinical Cardiology, and the Council on Cardiovascular Radiology and Intervention: endorsed by the American College of Cardiology Foundation, the North American Society for Cardiac Imaging, and the Society for Cardiovascular Magnetic Resonance. Circulation 2007;116:2878-91.

[106] Kaasalainen T, Pakarinen S, Kivisto S, et al. MRI with cardiac pacing devices - safety in clinical practice. Eur J Radiol 2014;83:1387-95.

[107] Kadish A, Dyer A, Daubert JP, et al. Prophylactic defibrillator implantation in patients with non-ischemic dilated cardiomyopathy. N Engl J Med 2004;350:2151-8.

[108] Krahn AD, Connolly SJ, Roberts RS, Gent M, Investigators A. Diminishing proportional risk of sudden death with advancing age: implications for prevention of sudden death. Am Heart J 2004;147:837-40.

[109] Al-Khatib SM, Greiner MA, Peterson ED, Hernandez AF, Schulman KA, Curtis LH. Patient and implanting physician factors associated with mortality and complications after implantable cardioverter defibrillator implantation, 2002-2005. Circ Arrhythm Electrophysiol 2008;1:240-9.

[110] Duray G, Richter S, Manegold J, Israel CW, Gronefeld G, Hohnloser SH. Efficacy and safety of ICD therapy in a population of elderly patients treated with optimal background medication. J Interv Card Electrophysiol 2005;14:169-73.

[111] Grimm W, Stula A, Sharkova J, Alter P, Maisch B. Outcomes of elderly recipients of implantable cardioverter defibrillators. Pacing Clin Electrophysiol 2007;30(Suppl. 1):S134-8.

[112] Noseworthy PA, Lashevsky I, Dorian P, Greene M, Cvitkovic S, Newman D. Feasibility of implantable cardioverter defibrillator use in elderly patients: a case series of octogenarians. Pacing Clin Electrophysiol 2004;27:373-8.

[113] Reynolds MR, Cohen DJ, Kugelmass AD, et al. The frequency and incremental cost of major complications among medicare beneficiaries receiving implantable cardioverter defibrillators. J Am Coll Cardiol 2006;47:2493-7.

[114] van Rees JB, Borleffs CJ, Thijssen J, et al. Prophylactic implantable cardioverter defibrillator treatment in the elderly: therapy, adverse events, and survival gain. Europace 2012;14:66-73.

[115] Fauchier L, Marijon E, Defaye P, et al. Effect of age on survival and causes of death after primary prevention implantable cardioverter defibrillator implantation. Am J Cardiol 2015;115:1415-22.

[116] Lee DS, Krahn AD, Healey JS, et al. Evaluation of early complications related to de novo cardioverter defibrillator implantation insights from the Ontario ICD database. J Am Coll Cardiol 2010;55:774-82.
[117] Yung D, Birnie D, Dorian P, et al. Survival after implantable cardioverter defibrillator implantation in the elderly. Circulation 2013;127:2383-92.

[118] Haines DE, Wang Y, Curtis J. Implantable cardioverter defibrillator registry risk score models for acute procedural complications or death after implantable cardioverter defibrillator implantation. Circulation 2011;123: 2069-76.

[119] Kirkfeldt RE, Johansen JB, Nohr EA, Jorgensen OD, Nielsen JC. Complications after cardiac implantable electronic device implantations: an analysis of a complete, nationwide cohort in Denmark. Eur Heart J 2014;35:1186-94.

[120] Goonewardene M, Barra S, Heck P, et al. Cardioverter defibrillator implantation and generator replacement in the octogenarian. Europace 2015;17:409-16.

[121] Pellegrini CN, Lee K, Olgin JE, et al. Impact of advanced age on survival in patients with implantable cardioverter defibrillators. Europace 2008;10:1296-301.

[122] Bristow MR, Saxon LA, Boehmer J, et al. Cardiac resynchronization therapy with or without an implantable defibrillator in advanced chronic heart failure. N Engl J Med 2004;350:2140-50.

[123] Ermis C, Zhu AX, Vanheel L, et al. Comparison of ventricular arrhythmia burden, therapeutic interventions, and survival, in patients $<75$ and patients or $\geq 75$ years of age treated with implantable cardioverter defibrillators. Europace 2007;9:270-4.

[124] Suleiman M, Goldenberg I, Haim M, et al. Clinical characteristics and outcomes of elderly patients treated with an implantable cardioverter defibrillator or cardiac resynchronization therapy in a real-world setting: data from the Israeli ICD Registry. Heart Rhythm 2014;11:435-41.

[125] Buxton AE, Lee KL, Hafley GE, et al. Limitations of ejection fraction for prediction of sudden death risk in patients with coronary artery disease: lessons from the MUSTT study. J Am Coll Cardiol 2007;50:1150-7.

[126] Bilchick KC, Stukenborg GJ, Kamath S, Cheng A. Prediction of mortality in clinical practice for medicare patients undergoing defibrillator implantation for primary prevention of sudden cardiac death. J Am Coll Cardiol 2012;60: 1647-55.

[127] Germano JJ, Reynolds M, Essebag V, Josephson ME. Frequency and causes of implantable cardioverter defibrillator therapies: is device therapy proarrhythmic? Am J Cardiol 2006;97:1255-61.

[128] van Rees JB, Borleffs CJ, de Bie MK, et al. Inappropriate implantable cardioverter defibrillator shocks: incidence, predictors, and impact on mortality. J Am Coll Cardiol 2011;57:556-62.

[129] Clementy N, Pierre B, Lallemand B, et al. Long-term follow-up on high-rate cut-off programming for implantable cardioverter defibrillators in primary prevention patients with left ventricular systolic dysfunction. Europace 2012;14:968-74.

[130] Gasparini M, Proclemer A, Klersy C, et al. Effect of long-detection interval vs. standard-detection interval for implantable cardioverter defibrillators on antitachycardia pacing and shock delivery: the ADVANCE III randomized clinical trial. JAMA 2013;309:1903-11.

[131] Moss AJ, Schuger C, Beck CA, et al. Reduction in inappropriate therapy and mortality through ICD programming. N Engl J Med 2012;367:2275-83.

[132] Wilkoff BL, Williamson BD, Stern RS, et al. Strategic programming of detection and therapy parameters in implantable cardioverter defibrillators reduces shocks in primary prevention patients: results from the PREPARE (Primary Prevention Parameters Evaluation) study. J Am Coll Cardiol 2008;52:541-50. 
[133] Kremers MS, Hammill SC, Berul CI, et al. The National ICD Registry Report: version 2.1 including leads and pediatrics for years 2010 and 2011. Heart Rhythm 2013;10:e59-65.

[134] Barra S, Providencia R, Paiva L, Heck P, Agarwal S. Implantable cardioverter defibrillators in the elderly: rationale and specific age-related considerations. Europace 2015;17:174-86.

[135] Bigger Jr JT. Prophylactic use of implanted cardiac defibrillators in patients at high risk for ventricular arrhythmias after coronary-artery bypass graft surgery. Coronary Artery Bypass Graft (CABG) Patch Trial Investigators. N Engl J Med 1997;337:1569-75.

[136] Hohnloser SH, Kuck KH, Dorian P, et al. Prophylactic use of an implantable cardioverter defibrillator after acute myocardial infarction. N Engl J Med 2004;351:2481-8.

[137] Gasparini M, Menozzi C, Proclemer A, et al. A simplified biventricular defibrillator with fixed long detection intervals reduces implantable cardioverter defibrillator (ICD) interventions and heart failure hospitalizations in patients with non-ischaemic cardiomyopathy implanted for primary prevention: the RELEVANT [Role of long dEtection window programming in patients with LEft VentriculAr dysfunction. Non-ischemic eTiology in primary prevention treated with a biventricular ICD] study. Eur Heart J 2009;30:2758-67.

[138] Saeed M, Hanna I, Robotis D, et al. Programming implantable cardioverter defibrillators in patients with primary prevention indication to prolong time to first shock: results from the PROVIDE study. J Cardiovasc Electrophysiol 2014;25:52-9.

[139] Wathen MS, DeGroot PJ, Sweeney MO, et al. Prospective randomized multicenter trial of empirical antitachycardia pacing versus shocks for spontaneous rapid ventricular tachycardia in patients with implantable cardioverter defibrillators: Pacing Fast Ventricular Tachycardia Reduces Shock Therapies (PainFREE Rx II) trial results. Circulation 2004;110:2591-6.

[140] Wilkoff BL, Fauchier L, Stiles MK, et al. 2015 HRS/EHRA/APHRS/SOLAECE expert consensus statement on optimal implantable cardioverter defibrillator programming and testing. Heart Rhythm 2016;13:e50-86.

[141] Cleland JG, Daubert JC, Erdmann E, et al. Longer-term effects of cardiac resynchronization therapy on mortality in heart failure [the CArdiac REsynchronization-Heart Failure (CAREHF) trial extension phase]. Eur Heart J 2006;27:1928-32.

[142] Cleland JG, Abraham WT, Linde C, et al. An individual patient meta-analysis of five randomized trials assessing the effects of cardiac resynchronization therapy on morbidity and mortality in patients with symptomatic heart failure. Eur Heart J 2013;34:3547-56.

[143] Ruschitzka F, Abraham WT, Singh JP, et al. Cardiac resynchronization therapy in heart failure with a narrow QRS complex. N Engl J Med 2013;369:1395-405.

[144] Goldenberg I, Moss AJ, Hall WJ, et al. Predictors of response to cardiac resynchronization therapy in the Multicenter Automatic Defibrillator Implantation Trial with Cardiac Resynchronization Therapy (MADIT-CRT). Circulation 2011;124:1527-36.

[145] Killu AM, Wu JH, Friedman PA, et al. Outcomes of cardiac resynchronization therapy in the elderly. Pacing Clin Electrophysiol 2013;36:664-72.

[146] Kuperstein R, Goldenberg I, Moss AJ, et al. Left atrial volume and the benefit of cardiac resynchronization therapy in the MADIT-CRT trial. Circ Heart Fail 2014;7:154-60.

[147] Penn J, Goldenberg I, Moss AJ, et al. Improved outcome with preventive cardiac resynchronization therapy in the elderly: a MADIT-CRT substudy. J Cardiovasc Electrophysiol 2011;22:892-7.

[148] Theuns DA, Schaer BA, Soliman OI, et al. The prognosis of implantable defibrillator patients treated with cardiac resynchronization therapy: comorbidity burden as predictor of mortality. Europace 2011;13:62-9.
[149] Khatib M, Tolosana JM, Trucco E, et al. EAARN score, a predictive score for mortality in patients receiving cardiac resynchronization therapy based on pre-implantation risk factors. Eur J Heart Fail 2014;16:802-9.

[150] Singh JP, Klein HU, Huang DT, et al. Left ventricular lead position and clinical outcome in the multicenter automatic defibrillator implantation trial-cardiac resynchronization therapy (MADIT-CRT) trial. Circulation 2011;123:1159-66.

[151] Kosmala W, Marwick TH. Meta-analysis of effects of optimization of cardiac resynchronization therapy on left ventricular function, exercise capacity, and quality of life in patients with heart failure. Am J Cardiol 2014;113:988-94.

[152] Rinaldi CA, Burri $H$, Thibault B, et al. A review of multisite pacing to achieve cardiac resynchronization therapy. Europace 2015;17:7-17.

[153] Anselme F, Bordachar P, Pasquie JL, et al. Safety, feasibility, and outcome results of cardiac resynchronization with triplesite ventricular stimulation compared to conventional cardiac resynchronization. Heart Rhythm 2016;13:183-9.

[154] Heidenreich PA, Tsai V, Bao H, et al. Does age influence cardiac resynchronization therapy use and outcome? JACC Heart Fail 2015;3:497-504.

[155] Kelli HM, Merchant FM, Mengistu A, Casey M, Hoskins M, El-Chami MF. Intermediate-term mortality and incidence of ICD therapy in octogenarians after cardiac resynchronization therapy. J Geriatr Cardiol 2014;11:180-4.

[156] Achilli A, Turreni F, Gasparini M, et al. Efficacy of cardiac resynchronization therapy in very old patients: the Insync/Insync ICD Italian Registry. Europace 2007;9:732-8.

[157] Inada K, Roberts-Thomson KC, Seiler J, et al. Mortality and safety of catheter ablation for antiarrhythmic drug-refractory ventricular tachycardia in elderly patients with coronary artery disease. Heart Rhythm 2010;7:740-4.

[158] Piccini JP, Berger JS, O'Connor CM. Amiodarone for the prevention of sudden cardiac death: a meta-analysis of randomized controlled trials. Eur Heart J 2009;30:1245-53.

[159] Cleland JG, Freemantle N, Erdmann E, et al. Long-term mortality with cardiac resynchronization therapy in the Cardiac Resynchronization-Heart Failure (CARE-HF) trial. Eur J Heart Fail 2012;14:628-34.

[160] Marijon E, Leclercq C, Narayanan K, et al. Causes-of-death analysis of patients with cardiac resynchronization therapy: an analysis of the CeRtiTuDe cohort study. Eur Heart $J$ 2015;36:2767-76.

[161] Tuppin P, Neumann A, Marijon E, et al. Implantation and patient profiles for pacemakers and cardioverter defibrillators in France (2008-2009). Arch Cardiovasc Dis 2011;104:332-42.

[162] Mandawat A, Curtis JP, Mandawat A, Njike VY, Lampert R. Safety of pacemaker implantation in nonagenarians: an analysis of the healthcare cost and utilization project-nationwide inpatient sample. Circulation 2013;127:1453-65 [65e1-2].

[163] Johansen JB, Jorgensen OD, Moller M, Arnsbo P, Mortensen PT, Nielsen JC. Infection after pacemaker implantation: infection rates and risk factors associated with infection in a population-based cohort study of 46299 consecutive patients. Eur Heart J 2011;32:991-8.

[164] Udo EO, van Hemel NM, Zuithoff NP, et al. Long-term outcome of cardiac pacing in octogenarians and nonagenarians. Europace 2012;14:502-8.

[165] Udo EO, Zuithoff NP, van Hemel NM, et al. Incidence and predictors of short- and long-term complications in pacemaker therapy: the FOLLOWPACE study. Heart Rhythm 2012;9:728-35.

[166] Wilkoff BL, Auricchio A, Brugada J, et al. HRS/EHRA Expert Consensus on the Monitoring of Cardiovascular Implantable Electronic Devices (CIEDs): description of techniques, indications, personnel, frequency and ethical considerations: 
developed in partnership with the Heart Rhythm Society (HRS) and the European Heart Rhythm Association (EHRA); and in collaboration with the American College of Cardiology (ACC), the American Heart Association (AHA), the European Society of Cardiology (ESC), the Heart Failure Association of ESC (HFA), and the Heart Failure Society of America (HFSA). Endorsed by the Heart Rhythm Society, the European Heart Rhythm Association (a registered branch of the ESC), the American College of Cardiology, the American Heart Association. Europace 2008;10:707-25.

[167] Laurent G, Amara W, Mansourati J, et al. Role of patient education in the perception and acceptance of home monitoring after recent implantation of cardioverter defibrillators: the EDUCAT study. Arch Cardiovasc Dis 2014;107:508-18.

[168] Ricci RP, Morichelli L, Quarta L, et al. Long-term patient acceptance of and satisfaction with implanted device remote monitoring. Europace 2010;12:674-9.

[169] Folino AF, Breda R, Calzavara P, et al. Remote follow-up of pacemakers in a selected population of debilitated elderly patients. Europace 2013;15:382-7.

[170] DeCicco AE, Finkel JB, Greenspon AJ, Frisch DR. Clinical significance of atrial fibrillation detected by cardiac implantable electronic devices. Heart Rhythm 2014;11:719-24.

[171] Orlov MV, Ghali JK, Araghi-Niknam M, et al. Asymptomatic atrial fibrillation in pacemaker recipients: incidence, progression, and determinants based on the atrial high rate trial. Pacing Clin Electrophysiol 2007;30:404-11.

[172] Glotzer TV, Daoud EG, Wyse DG, et al. The relationship between daily atrial tachyarrhythmia burden from implantable device diagnostics and stroke risk: the TRENDS study. Circ Arrhythm Electrophysiol 2009;2:474-80.

[173] Glotzer TV, Hellkamp AS, Zimmerman J, et al. Atrial high rate episodes detected by pacemaker diagnostics predict death and stroke: report of the Atrial Diagnostics Ancillary Study of the MOde Selection Trial (MOST). Circulation 2003;107:1614-9.

[174] Healey JS, Connolly SJ, Gold MR, et al. Subclinical atrial fibrillation and the risk of stroke. N Engl J Med 2012;366:120-9.

[175] Capucci A, Santini M, Padeletti L, et al. Monitored atrial fibrillation duration predicts arterial embolic events in patients suffering from bradycardia and atrial fibrillation implanted with antitachycardia pacemakers. J Am Coll Cardiol 2005;46:1913-20.

[176] Martin DT, Bersohn MM, Waldo AL, et al. Randomized trial of atrial arrhythmia monitoring to guide anticoagulation in patients with implanted defibrillator and cardiac resynchronization devices. Eur Heart J 2015;36:1660-8.

[177] Brambatti M, Connolly SJ, Gold MR, et al. Temporal relationship between subclinical atrial fibrillation and embolic events. Circulation 2014;129:2094-9.

[178] Daoud EG, Glotzer TV, Wyse DG, et al. Temporal relationship of atrial tachyarrhythmias, cerebrovascular events, and systemic emboli based on stored device data: a subgroup analysis of TRENDS. Heart Rhythm 2011;8:1416-23.
[179] Goldenberg I, Kutyifa V, Klein HU, et al. Survival with cardiac resynchronization therapy in mild heart failure. N Engl J Med 2014;370:1694-701.

[180] Landolina M, Gasparini M, Lunati M, et al. Long-term complications related to biventricular defibrillator implantation: rate of surgical revisions and impact on survival: insights from the Italian Clinical Service Database. Circulation 2011;123:2526-35.

[181] Kini V, Soufi MK, Deo R, et al. Appropriateness of primary prevention implantable cardioverter defibrillators at the time of generator replacement: are indications still met? J Am Coll Cardiol 2014;63:2388-94.

[182] Aktas MK, Goldenberg I, Moss AJ, et al. Comparison of age ( $<75$ years versus $\geq 75$ years) to risk of ventricular tachyarrhythmias and implantable cardioverter defibrillator shocks (from the Multicenter Automatic Defibrillator Implantation Trial With Cardiac Resynchronization Therapy). Am J Cardiol 2014;114:1855-60.

[183] Wright GA, Klein GJ, Gula LJ. Ethical and legal perspec tive of implantable cardioverter defibrillator deactivation or implantable cardioverter defibrillator generator replacement in the elderly. Curr Opin Cardiol 2013;28:43-9.

[184] Grubb BP, Karabin B. Ethical dilemmas and end-of-life choices for patients with implantable cardiac devices: decisions regarding discontinuation of therapy. Curr Treat Options Cardiovasc Med 2011;13:385-92.

[185] Dodson JA, Fried TR, Van Ness PH, Goldstein NE, Lampert R. Patient preferences for deactivation of implantable cardioverter defibrillators. JAMA Intern Med 2013;173: 377-9.

[186] Padeletti L, Arnar DO, Boncinelli L, et al. EHRA Expert Consensus Statement on the management of cardiovascular implantable electronic devices in patients nearing end of life or requesting withdrawal of therapy. Europace 2010;12:1480-9.

[187] Reddy VY, Knops RE, Sperzel J, et al. Permanent leadless cardiac pacing: results of the LEADLESS trial. Circulation 2014;129:1466-71.

[188] Reddy VY, Exner DV, Cantillon DJ, et al. Percutaneous Implantation of an entirely intracardiac leadless pacemaker. N Engl J Med 2015;373:1125-35.

[189] Reynolds D, Duray GZ, Omar R, et al. A leadless intracardiac transcatheter pacing system. N Engl J Med 2016;374:533-41.

[190] Zebda A, Gondran C, Le Goff A, Holzinger M, Cinquin P, Cosnier S. Mediatorless high-power glucose biofuel cells based on compressed carbon nanotube-enzyme electrodes. Nat Commun 2011;2:370.

[191] McLeod CJ, Boersma L, Okamura H, Friedman PA. The subcutaneous implantable cardioverter defibrillator: stateof-the-art review. Eur Heart J 2015 [Epub ahead of print. pii: ehv507].

[192] Lewis GF, Gold MR. Clinical experience with subcutaneous implantable cardioverter defibrillators. Nat Rev Cardiol 2015;12:398-405. 